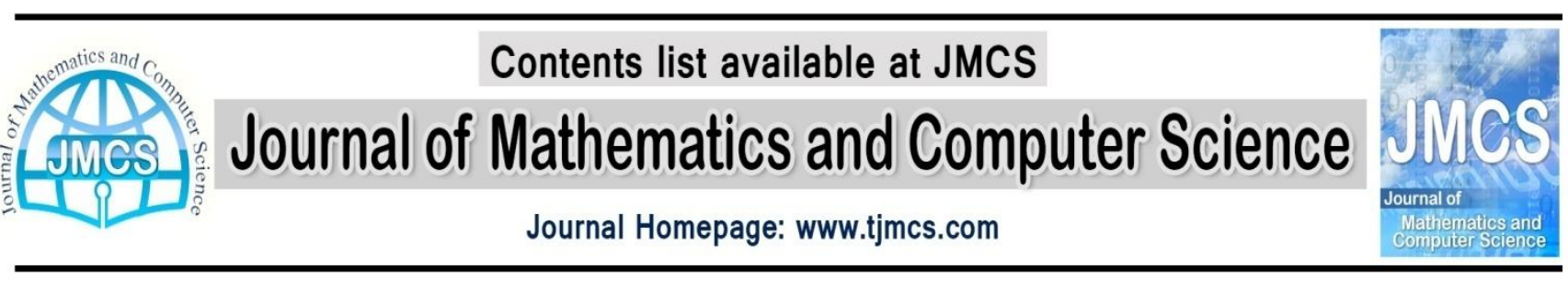

\title{
Coupled fixed point results for mappings involving $(\alpha, \psi)$ - weak contractions in ordered metric spaces and applications
}

\author{
Manish Jain*, Neetu Gupta, Sanjay Kumar \\ Department of Mathematics, Ahir College, Rewari 123401, India \\ HAS Department, YMCAUST, Faridabad, India \\ Department of Mathematics, DCRUST, Muthal, Soneptal, India
}

Article history:

E-mail manish_261283@rediffmail.com

Received January 2014

Accepted March 2014

Available online March 2014

\begin{abstract}
In this paper we introduce the notion of $(\alpha, \psi)$ - weak contractions and use the notion to establish the existence and uniqueness of coupled common fixed points for the mixed monotone operators in partially ordered metric spaces. The obtained results extend, improve, complement and unify many recent coupled fixed point results present in the literature. The theoretic results are accompanied with suitable examples. An application to the existence and uniqueness of the solution of the system of integral equations is also presented.
\end{abstract}

Keywords: Mixed g-monotone property; $(\alpha, \psi)$ - weak contractions; Coupled coincidence point; Coupled common fixed point.

\section{Introduction and preliminaries}

Banach [1] in his classical work gave the following contractive theorem:

Theorem 1.1 ([1]). Let $(X, d)$ be a metric space and $T: X \rightarrow X$ be a self mapping. If $(X, d)$ is complete and $T$ is a contraction; that is, there exists a constant $k \in[0,1)$ such that

$$
d(T x, T y) \leq k d(x, y), \text { for all } x, y \in X
$$

then, $T$ has a unique fixed point $u \in X$ and for any $x_{0} \in X$, the Picard iteration $\left\{T^{n}\left(x_{0}\right)\right\}$ converges to $u$.

This contraction principle proved to be a very important tool in nonlinear analysis, and various authors have generalized it in many ways. One can refer to the works noted in references ([2-17]). 
Turinici [16] laid the foundation of new era in fixed point theory by extending the Banach contraction principle to the partially ordered sets. Ran and Reurings [17] developed some applications of Turinici's theorem to matrix equations. Guo and Lakshmikantham [18] defined the concept of coupled fixed point.

Definition 1.1 ([18]). An element $(x, y) \in X \times X$, is called a coupled fixed point of the mapping $F: X \times X \rightarrow X$ if

$$
F(x, y)=x \text { and } F(y, x)=y .
$$

Bhaskar and Lakshmikantham [19] proved the existence and uniqueness of coupled fixed point for mappings satisfying the mixed monotone property in partially ordered metric spaces. As an application, they discussed the existence and uniqueness of the solution for a periodic boundary value problem.

Definition 1.2 ([19]). Let $(X, \leq)$ be a partially ordered set and $F: X \times X \rightarrow F$. The mapping $F$ is said to have the mixed monotone property if $F(x, y)$ is monotone non-decreasing in $x$ and monotone non-increasing in $y$; that is, for any $x, y \in X$,

$$
x_{1}, x_{2} \in X, \quad x_{1} \leq x_{2} \text { implies } F\left(x_{1}, y\right) \leq F\left(x_{2}, y\right)
$$

and

$$
y_{1}, y_{2} \in X, \quad y_{1} \leq y_{2} \text { implies } F\left(x, y_{1}\right) \geq F\left(x, y_{2}\right) .
$$

Bhaskar and Lakshmikantham [19] proved the following main result.

Theorem 1.2 ([19]). Let $(X, \leq)$ be a partially ordered set and $d$ be a metric on $X$ such that $(X, d)$ is a complete metric space. Let $F: X \times X \rightarrow X$ be a continuous mapping having the mixed monotone property on $X$. Assume that there exists a $k$ in $[0,1)$ with

$$
d(F(x, y), F(u, v)) \leq \frac{k}{2}[d(x, y), d(y, v)] \text { for each } x \geq u, y \leq v .
$$

If there exists $x_{0}, y_{0}$ in $X$ such that

$$
x_{0} \leq F\left(x_{0}, y_{0}\right) \text { and } y_{0} \geq F\left(y_{0}, x_{0}\right)
$$

then there exists $x, y$ in $X$ such that

$$
x=F(x, y) \quad \text { and } \quad F(y, x) .
$$

In [19, Theorem 2.2], it has also been shown that the continuity assumption of $F$ in Theorem 1.2 can be replaced by an alternative condition imposed on convergent non-decreasing and nonincreasing sequences.

Assumption 1.1. $X$ has the property that

(i) if a non-decreasing sequence $\left\{x_{n}\right\} \subset X$ converges to $x$, then $x_{n} \leq x$ for all $n$,

(ii) if a non-increasing sequence $\left\{x_{n}\right\} \subset X$ converges to $x$, then $x_{n} \geq x$ for all $n$. 
Berinde [20, Theorem 3], in an alternative way generalized the results of Bhaskar and Lakshmikantham [19] under a weaker contraction given below:

$$
d(F(x, y), F(u, v))+d(F(y, x), F(v, u)) \leq k[d(x, u)+d(y, v)],
$$

with $x \geq u$ and $y \leq v$, where $k \in[0,1)$.

On the other hand, Lakshmikantham and Ćiric [21] extended the notion of mixed monotone property to mixed $g$-monotone property and generalized the results proved in [19] by establishing the existence of coupled coincidence point results using a pair of commutative mappings. This generated new trends in coupled fixed point theory with applications to partially ordered sets. Since then much work has been done in this direction by different authors. For more details the reader may consult ([22-38]).

Definition 1.3 ([21]). Let $(X, \leq)$ be a partially ordered set and $F: X \times X \rightarrow X$ and $g: X \times X \rightarrow X$. We say $F$ has the mixed $g$-monotone property if $F$ is monotone $g$-nondecreasing in its first argument and is monotone $g$-nonincreasing in its second argument; that is, for any $x, y \in X$,

$$
x_{1}, x_{2} \in X, \quad g x_{1} \leq g x_{2} \quad \text { implies } \quad F\left(x_{1}, y\right) \leq F\left(x_{2}, y\right)
$$

and

$$
y_{1}, y_{2} \in X, \quad g y_{1} \leq g y_{2} \quad \text { implies } \quad F\left(x, y_{1}\right) \geq F\left(x, y_{2}\right) \text {. }
$$

Definition 1.4 ([21]). An element $(x, y) \in X \times X$, is called a coupled coincidence point of the mappings $F: X \times X \rightarrow X$ and $g: X \rightarrow X$ if

$F(x, y)=g x \quad$ and $\quad F(y, x)=g y$.

Definition 1.5 ([21]). Let $X$ be a non-empty set and $F: X \times X \rightarrow X$ and $g: X \rightarrow X$. We say that $F$ and $g$ are commutative if

$$
g(F(x, y))=\mathrm{F}(g(x), g(y))
$$

for all $x, y \in X$.

Later, Choudhury et al. [22] introduced the notion of compatible mappings in context of coupled coincidence point problems and used the notion to improve the results noted in [21].

Definition 1.6 ([22]). The mappings $\mathrm{F}$ and g where $F: X \times X \rightarrow X g: X \rightarrow X$ are said to be compatible if

$$
\lim _{n \rightarrow \infty} d\left(g F\left(x_{n}, y_{n}\right), F\left(g x_{n}, g y_{n}\right)\right)=0
$$

and

$$
\lim _{n \rightarrow \infty} d\left(g F\left(y_{n}, x_{n}\right), F\left(g y_{n}, g x_{n}\right)\right)=0,
$$

where $\left\{x_{n}\right\}$ and $\left\{y_{n}\right\}$ are sequences in $X$ such that $\lim _{n \rightarrow \infty} F\left(x_{n}, y_{n}\right)=\lim _{n \rightarrow \infty} g x_{n}=x$ and $\lim _{n \rightarrow \infty} F\left(y_{n}, x_{n}\right)=\lim _{n \rightarrow \infty} g y_{n}=y$ for all $x, y \in X$ are satisfied. 
Jain et al. [38], extended Berinde's contraction (1.3) for a pair of compatible mappings and obtained coupled coincidence points under the following contraction:

$$
d(F(x, y), F(u, v))+d(F(y, x), F(v, u)) \leq k[d(g x, g u)+d(g y, g v)] .
$$

Denote with $\Psi$ the family of non-decreasing functions $\psi:[0,+\infty) \rightarrow[0,+\infty)$ such that $\sum_{n=0}^{\infty} \psi^{n}(t)<$ $+\infty$ for all $t>0$, where $\psi^{n}$ is the nth iterate of $\psi$.

These functions are popularly known as $(c)$-comparison functions in the literature and it can be easily seen that if $\psi$ is a (c)-comparison function, then $\psi(t)<t$ for any $t>0$.

In 2012, Samet et al. [39] introduced the notions of $\alpha-\psi$-contractive and $\alpha$-admissible mappings and used the notions to establish the existence of fixed points in complete metric spaces. The work presented in the paper [39] generalized and extended the famous Banach contraction principle and the works noted in the references $[17,10,19]$.

Definition 1.7 ([39]). Let $(X, d)$ be a metric space and let $T: X \rightarrow X$ be a given mapping. We say that $T$ is an $\alpha$ - $\psi$-contractive mapping if there exist two functions $\alpha: X \times X \rightarrow[0,+\infty)$ and $\psi \in \Psi$ such that

$$
\alpha(x, y) d(T x, T y) \leq \psi(d(x, y)), \text { for all } x, y \in X .
$$

Interestingly, a mapping satisfying Banach Contraction condition (that is, condition (1.1)), is an $\alpha$ - $\psi$ contractive mapping with $\alpha(x, y)=1$ for all $\mathrm{x}, \mathrm{y} \in \mathrm{X}$ and $\psi(t)=\mathrm{kt}, \mathrm{k} \in[0,1)$.

Definition 1.8 ([39]). Let $T: X \rightarrow X$ and $\alpha: X \times X \rightarrow[0,+\infty)$. We say that $T$ is $\alpha$-admissible if for all $x, y \in X$, we have

$$
\alpha(x, y) \geq 1 \Rightarrow \alpha(T x, T y) \geq 1 \text {. }
$$

Examples of such mappings are presented in [39].

Mursaleen et al. [40] defined $(\alpha, \psi)$-contractive mappings and extended the notion of $\alpha$ admissible mappings to obtain coupled fixed points in the setting of metric spaces endowed with partial ordering.

Definition 1.9 ([40]). Let $F: X \times X \rightarrow X$ and $\alpha: X^{2} \times X^{2} \rightarrow[0,+\infty)$ be two mappings. Then $F$ is said to be $(\alpha)$-admissible if

$$
\alpha((x, y),(u, v)) \geq 1 \Rightarrow \alpha((F(x, y), F(y, x)),(F(u, v), F(v, u))) \geq 1
$$

for all $x, y, u, v \in X$.

Definition 1.10 ([40]). Let $(X, d)$ be a partially ordered metric space and $F: X \times X \rightarrow X$ be a mapping. Then the mapping $F$ is said to be $(\alpha, \psi)$-contractive if there exist two functions $\alpha: X^{2} \times X^{2} \rightarrow[0,+\infty)$ and $\psi \in \Psi$ such that 


$$
\alpha((x, y),(u, v)) d(F(x, y), F(u, v)) \leq \psi\left(\frac{d(x, u)+d(y, v)}{2}\right)
$$

for all $x, y, u, v \in X$ with $x \geq u$ and $y \leq v$.

Very recently, Karapinar and Agarwal [41] weakened the contraction (1.6) by considering more general contractive condition. We summarize the main results in [41, Theorems 2.1 and 2.2] as:

Theorem 1.3 ([41]). Let $(X, \leq)$ be a partially ordered set, and suppose that there is a metric $d$ on $X$ such that $(X, d)$ is a complete metric space. Let $F: X \times X \rightarrow X$ be a mapping having the mixed monotone property on $X$. Suppose that there exist $\psi \in \Psi$ and $\alpha: X^{2} \times X^{2} \rightarrow[0,+\infty)$ such that for all $x, y, u, v \in X$, the following holds:

$$
\alpha((x, y),(u, v))\left(\frac{d(F(x, y), F(u, v))+d(F(y, x), F(v, u))}{2}\right) \leq \psi\left(\frac{d(x, u)+d(y, v)}{2}\right),
$$

for which $x \geq u$ and $y \leq v$. Suppose also that

(i) $F$ is $(\alpha)$-admissible,

(ii) there exist $x_{0}, y_{0} \in X$ such that

$$
\alpha\left(\left(x_{0}, y_{0}\right),\left(F\left(x_{0}, y_{0}\right), F\left(y_{0}, x_{0}\right)\right)\right) \geq 1 \quad \text { and } \quad \alpha\left(\left(y_{0}, x_{0}\right),\left(F\left(y_{0}, x_{0}\right), F\left(x_{0}, y_{0}\right)\right)\right) \geq 1 \text {; }
$$

(iii) either $F$ is continuous or the following property hold:

if $\left\{x_{n}\right\}$ and $\left\{y_{n}\right\}$ are sequences in $X$ such that $\alpha\left(\left(x_{n}, y_{n}\right),\left(x_{n+1}, y_{n+1}\right)\right) \geq 1$ and $\alpha\left(\left(y_{n}, x_{n}\right),\left(y_{n+1}, x_{n+1}\right)\right) \geq 1$ for all $n$, and $\lim _{n \rightarrow \infty} x_{n}=x$ and $\lim _{n \rightarrow \infty} y_{n}=y$, then $\alpha\left(\left(x_{n}, y_{n}\right),(x, y)\right) \geq 1$ and $\alpha\left(\left(y_{n}, x_{n}\right),(y, x)\right) \geq 1$ for all $n$.

If there exist $x_{0}, y_{0} \in X$ such that $x_{0} \leq F\left(x_{0}, y_{0}\right)$ and $y_{0} \geq F\left(y_{0}, x_{0}\right)$, then $F$ has a coupled fixed point; that is, there exist $x, y \in X$ such that

$$
F(x, y)=x \text { and } y=F(y, x) \text {. }
$$

Now, we introduce our notions:

Definition 1.11. Let $(X, d)$ be a partially ordered metric space and $F: X \times X \rightarrow X$, then $F$ is said to be $(\alpha, \psi)$ - weak contraction if there exist two functions $\alpha: X^{2} \times X^{2} \rightarrow[0,+\infty)$ and $\psi \in \Psi$ such that

$$
\alpha((x, y),(u, v))\left(\frac{\mathrm{d}(F(x, y), F(u, v))+\mathrm{d}(F(y, x), F(v, u))}{2}\right) \leq \psi\left(\frac{d(x, u)+d(y, v)}{2}\right),
$$

for all $x, y, u, v \in X$ with $x \geq u$ and $y \leq u$ (or $x \leq u$ and $y \geq v$ ).

Definition 1.12. Let $(X, d)$ be a partially ordered metric space and $F: X \times X \rightarrow X$ and $g: X \rightarrow X$ be two mappings. Then $F$ is said to be $(\alpha, \psi)$ - weak contraction with respect to $g$, if there exist two functions $\alpha: X^{2} \times X^{2} \rightarrow[0,+\infty)$ and $\psi \in \Psi$ such that

$$
\alpha((g x, g y),(g u, g v))\left(\frac{\mathrm{d}(F(x, y), F(u, v))+\mathrm{d}(F(y, x), F(v, u))}{2}\right) \leq \psi\left(\frac{d(g x, g u)+d(g y, g v)}{2}\right),
$$

for all $x, y, u, v \in X$ with $g x \geq g u$ and $g y \leq g v$ (or $g x \leq g u$ and $g y \geq g v$ ). 
Definition 1.13. Let $F: X \times X \rightarrow X, g: X \rightarrow X$ and $\alpha: X^{2} \times X^{2} \rightarrow[0,+\infty)$ be mappings. Then $F$ is said to be $(\alpha)$-admissible with respect to $g$ if

$$
\alpha((g x, g y),(g u, g v)) \geq 1 \Rightarrow \alpha((F(x, y), F(y, x)),(F(u, v), F(v, u))) \geq 1,
$$

for all $x, y, u, v \in X$.

If we replace $g$ with identity mapping in Definition 1.13 , we get the definition of $(\alpha)$-admissible mappings.

For a partially ordered set $(X, \leq)$, we endow $X \times X$ with the following order $\preccurlyeq$

$$
(u, v) \preccurlyeq(x, y) \Leftrightarrow u \leq x, y \leq v \text { for all }(x, y),(u, v) \in X \times X .
$$

We say that $(u, v)$ and $(x, y)$ are comparable if either $(u, v) \preccurlyeq(x, y)$ or $(x, y) \preccurlyeq(u, v)$.

However, in our theory, we use the same notation $\leq$ to denote the ordering in $X \times X$ and in $X$.

In this paper, we shall extend and improve the main result of Karapinar et al. [41] to the pair of compatible mappings. Our results generalize the recent results noted in [38], [20] and weakens the contractions involved in the works of Bhaskar and Lakshmikanthan [19] and Mursaleen et al. [40]. Suitable examples and applications to the system of integral equations are given to illustrate the usability of our obtained results.

\section{Main results}

Theorem 2.1. Let $(X, \leq)$ be a partially ordered set and there exists a metric $d$ on $X$ such that $(X, d)$ is a complete metric space. Let $F: X \times X \rightarrow X, g: X \rightarrow X$ be two mappings. Suppose that $F$ has the mixed $g$-monotone property and the mapping $g$ is continuous. Suppose there exists two functions $\alpha: X^{2} \times X^{2} \rightarrow[0,+\infty)$ and $\psi \in \Psi$ such that $F$ is $(\alpha, \psi)$ - weak contraction with respect to $g$.

Also suppose that

(i) $F$ is $(\alpha)$-admissible with respect to $g$;

(ii) there exist $x_{0}, y_{0} \in X$ such that

$$
\alpha\left(\left(g x_{0}, g y_{0}\right),\left(F\left(x_{0}, y_{0}\right), F\left(y_{0}, x_{0}\right)\right)\right) \geq 1 ;
$$

(iii) $F(X \times X) \subseteq g(X)$;

(iv) the pair $(F, g)$ is compatible;

(v) the mapping $F$ is continuous.

If in the hypotheses (ii), the elements $x_{0}, y_{0} \in X$ be chosen so that $g x_{0} \leq F\left(x_{0}, y_{0}\right)$ and $g y_{0} \leq$ $F\left(y_{0}, x_{0}\right)$, then the mappings $F$ and $g$ have a coupled coincidence point in $X$; that is, there exist $x, y \in X$ such that

$$
F(x, y)=g(x) \quad \text { and } \quad F(y, x)=g(y) .
$$

Proof. Let $x_{0}, y_{0} \in X$ be such that

$$
\alpha\left(\left(g x_{0}, g y_{0}\right),\left(F\left(x_{0}, y_{0}\right), F\left(y_{0}, x_{0}\right)\right)\right) \geq 1 .
$$


Since $F(X \times X) \subseteq g(X)$, we can choose $x_{1}, y_{1} \in X$ such that $g\left(x_{1}\right)=F\left(x_{0}, y_{0}\right), g\left(x_{1}\right)=F\left(y_{0}, x_{0}\right)$. Again we can choose $x_{2}, y_{2} \in X$ such that $\left(x_{2}\right)=F\left(x_{1}, y_{1}\right), g\left(y_{2}\right)=f\left(x_{1}, y_{1}\right)$.

Continuing this process, we can inductively construct sequences $\left(g x_{n}\right)$ and $\left(g y_{n}\right)$ in $X$ such that

$$
g\left(x_{n+1}\right)=F\left(x_{n}, y_{n}\right), g\left(y_{n+1}\right)=F\left(y_{n}, x_{n}\right), \quad \text { for all } n \geq 0
$$

We shall prove for all $n \geq 0$, that

$$
g x_{n} \leq g x_{n+1} \quad \text { and } \quad g y_{n} \geq g y_{n+1} .
$$

Since $g x_{0} \leq F\left(x_{0}, y_{0}\right)$ and $g y_{0} \geq F\left(y_{0}, x_{0}\right), \mathrm{g} x_{1}=\mathrm{F}\left(x_{0}, y_{0}\right), \mathrm{g} y_{1}=\mathrm{F}\left(y_{0}, x_{0}\right)$, we have $\mathrm{g} x_{0} \leq \mathrm{g} x_{1}, \mathrm{~g} y_{0} \geq$ $\mathrm{g} y_{1}$; that is, (2.2) holds for $\mathrm{n}=0$.

Suppose that (2.2) holds for some fixed $\mathrm{n}>0$; that is, $\mathrm{g} x_{n} \leq \mathrm{g} x_{n+1}, \mathrm{~g} y_{n} \geq \mathrm{g} y_{n+1}$. As $\mathrm{F}$ has the mixed $\mathrm{g}$ monotone property, using (2.1), we have

$$
\mathrm{g}\left(x_{n+1}\right)=\mathrm{F}\left(x_{n}, y_{n}\right) \leq \mathrm{F}\left(x_{n+1}, y_{n}\right) \leq \mathrm{F}\left(x_{n+1}, y_{n+1}\right)=\mathrm{g}\left(x_{n+2}\right),
$$

and

$$
\mathrm{g}\left(y_{n+1}\right)=\mathrm{F}\left(y_{n}, x_{n}\right) \geq \mathrm{F}\left(y_{n+1}, x_{n}\right) \geq \mathrm{F}\left(y_{n+1}, x_{n+1}\right)=\mathrm{g}\left(y_{n+2}\right) .
$$

Then by mathematical induction, it follows that (2.2) holds for all $n \geq 0$.

If for some $\mathrm{n} \geq 0$, we have $\left(\mathrm{g} x_{n+1}, \mathrm{~g} y_{n+1}\right)=\left(\mathrm{g} x_{n}, \mathrm{~g} y_{n}\right)$, then $\mathrm{F}\left(x_{n}, y_{n}\right)=\mathrm{g} x_{n}$ and $\mathrm{F}\left(y_{n}, x_{n}\right)=\mathrm{g} y_{n}$; that is, $\mathrm{F}$ and $\mathrm{g}$ have a coupled coincidence point. So now onwards, we suppose $\left(\mathrm{g} x_{n+1}, \mathrm{~g} y_{n+1}\right) \neq\left(\mathrm{g} x_{n}\right.$, $\left.\mathrm{g} y_{n}\right)$ for all $\mathrm{n} \geq 0$; that is, we suppose that either $\mathrm{g} x_{n+1}=\mathrm{F}\left(x_{n}, y_{n}\right) \neq \mathrm{g} x_{n}$ or $\mathrm{g} y_{n+1}=\mathrm{F}\left(y_{n}, x_{n}\right) \neq \mathrm{g} y_{n}$.

Since $\mathrm{F}$ is $(\alpha)$ - admissible with respect to $\mathrm{g}$, we have

$$
\begin{gathered}
\alpha\left(\left(g x_{0}, g y_{0}\right),\left(g x_{1}, g y_{1}\right)\right)=\alpha\left(\left(g x_{0}, g y_{0}\right),\left(\mathrm{F}\left(x_{0}, y_{0}\right), \mathrm{F}\left(y_{0}, x_{0}\right)\right)\right) \geq 1 \\
\Rightarrow \alpha\left(\left(\mathrm{F}\left(x_{0}, y_{0}\right), \mathrm{F}\left(y_{0}, x_{0}\right)\right),\left(\mathrm{F}\left(x_{1}, y_{1}\right), \mathrm{F}\left(y_{1}, x_{1}\right)\right)\right)=\alpha\left(\left(g x_{1}, g y_{1}\right),\left(g x_{2}, g y_{2}\right)\right) \geq 1 .
\end{gathered}
$$

Thus, using mathematical induction, we have

$$
\alpha\left(\left(g x_{n}, g y_{n}\right),\left(g x_{n+1}, g y_{n+1}\right)\right) \geq 1,
$$

for all $\mathrm{n} \in \mathbb{N}$. Since $\mathrm{F}$ is $(\alpha, \psi)$ - weak contraction with respect to $\mathrm{g}$, using (2.3), we obtain

$$
\begin{aligned}
& \frac{\mathrm{d}\left(g x_{n}, g x_{n+1}\right)+\mathrm{d}\left(g y_{n}, g y_{n+1}\right)}{2} \\
& \quad=\frac{\mathrm{d}\left(\mathrm{F}\left(x_{n-1}, y_{n-1}\right), \mathrm{F}\left(x_{n}, y_{n}\right)\right)+\mathrm{d}\left(\mathrm{F}\left(y_{n-1}, x_{n-1}\right), \mathrm{F}\left(y_{n}, x_{n}\right)\right)}{2} \\
& \quad \leq \alpha\left(\left(g x_{n-1}, g y_{n-1}\right),\left(g x_{n}, g y_{n}\right)\right)\left(\frac{\mathrm{d}\left(\mathrm{F}\left(x_{n-1}, y_{n-1}\right), \mathrm{F}\left(x_{n}, y_{n}\right)\right)+\mathrm{d}\left(\mathrm{F}\left(y_{n-1}, x_{n-1}\right), \mathrm{F}\left(y_{n}, x_{n}\right)\right)}{2}\right) \\
& \quad \leq \psi\left(\frac{\mathrm{d}\left(g x_{n-1}, g x_{n}\right)+\mathrm{d}\left(g y_{n-1}, g y_{n}\right)}{2}\right) .
\end{aligned}
$$

Repeating the above process, we get 


$$
\frac{\mathrm{d}\left(g x_{n}, g x_{n+1}\right)+\mathrm{d}\left(g y_{n}, g y_{n+1}\right)}{2} \leq \psi^{n}\left(\frac{d\left(g x_{0}, g x_{1}\right)+d\left(g y_{0}, g y_{1}\right)}{2}\right)
$$

for all $n \in \mathbb{N}$. For $\epsilon>0$ there exists $n(\epsilon) \in \mathbb{N}$ such that

$$
\sum_{n \geq n(\epsilon)} \psi^{n}\left(\frac{d\left(g x_{0}, g x_{1}\right)+d\left(g y_{0}, g y_{1}\right)}{2}\right)<\epsilon / 2 \text {. }
$$

Let $n, m \in \mathbb{N}$ be such that $m>n>n(\epsilon)$. Then, by using the triangle inequality, we obtain

$$
\begin{gathered}
\frac{\mathrm{d}\left(g x_{n}, g x_{m}\right)+\mathrm{d}\left(g y_{n}, g y_{m}\right)}{2} \leq \sum_{k=n}^{m-1} \frac{d\left(g x_{k}, g x_{k+1}\right)+d\left(g y_{k}, g y_{k+1}\right)}{2} \\
\leq \sum_{k=n}^{m-1} \psi^{k}\left(\frac{d\left(g x_{0}, g x_{1}\right)+d\left(g y_{0}, g y_{1}\right)}{2}\right) \\
\leq \sum_{n \geq n(\epsilon)} \psi^{n}\left(\frac{d\left(g x_{0}, g x_{1}\right)+d\left(g y_{0}, g y_{1}\right)}{2}\right)<\epsilon / 2 .
\end{gathered}
$$

This implies that $\mathrm{d}\left(g x_{n}, g x_{m}\right)+\mathrm{d}\left(g y_{n}, g y_{m}\right)<\epsilon$.

Hence, it follows that $\left(g x_{n}\right)$ and $\left(g y_{n}\right)$ are Cauchy sequences in $(\mathrm{X}, \mathrm{d})$, then using the completeness of $(X, d)$ there exist $x, y \in X$ such that

$$
\lim _{n \rightarrow \infty} \mathrm{F}\left(x_{n}, y_{n}\right)=\lim _{n \rightarrow \infty} g x_{n+1}=\mathrm{x} \text { and } \lim _{n \rightarrow \infty} \mathrm{F}\left(y_{n}, x_{n}\right)=\lim _{n \rightarrow \infty} g y_{n+1}=\mathrm{y} \text {. }
$$

Since, the pair $(F, g)$ is compatible, we have

$$
\begin{aligned}
& \lim _{n \rightarrow \infty} d\left(g\left(\mathrm{~F}\left(x_{n}, y_{n}\right)\right), F\left(g\left(x_{n}\right), g\left(y_{n}\right)\right)\right)=0 \\
& \lim _{n \rightarrow \infty} d\left(g\left(\mathrm{~F}\left(y_{n}, x_{n}\right)\right), F\left(g\left(y_{n}\right), g\left(x_{n}\right)\right)\right)=0 .
\end{aligned}
$$

Finally, we shall show that

$$
g(x)=F(x, y) \text { and } g(y)=F(y, x) .
$$

For all $\mathrm{n} \geq 0$, we have

$$
\mathrm{d}\left(g x, F\left(g x_{n}, g y_{n}\right)\right) \leq \mathrm{d}\left(g x, g\left(\mathrm{~F}\left(x_{n}, y_{n}\right)\right)\right)+\mathrm{d}\left(g\left(\mathrm{~F}\left(x_{n}, y_{n}\right)\right), F\left(g x_{n}, g y_{n}\right)\right)
$$

Taking the limit as $n \rightarrow \infty$ in (2.7), then by the continuities of $F$ and $g$, and using (2.5)-(2.6), we obtain $d(g(x), F(x, y))=0$ and hence $g(x)=F(x, y)$. Similarly, $g(y)=F(y, x)$.

Hence, we proved that $F$ and $g$ has coupled coincidence point.

Next, we discuss an example to support Theorem 2.1.

Example 2.1. Let $X=\mathbb{R}$. Then $(X, \leq)$ is a partially ordered set with the natural ordering of real numbers. Let $d: X \times X \rightarrow R^{+}$be defined by

$$
d(x, y)=|x-y| \text { for } x, y \in X \text {. }
$$

Then $(X, d)$ is a complete metric space.

Consider the mapping $\alpha: X^{2} \times X^{2} \rightarrow[0,+\infty)$ defined as 
$\alpha((x, y),(u, v))= \begin{cases}1, & \text { if } x \geq u, y \leq v, \text { or } x \leq u, y \geq v \\ 0, & \text { otherwise. }\end{cases}$

Let us define $:[0,+\infty) \rightarrow[0,+\infty)$ by $\psi(t)=\frac{3}{5} t$, for $t \in[0,+\infty)$.

Define $\mathrm{F}: \mathrm{X} \times \mathrm{X} \rightarrow \mathrm{X}$ by $\mathrm{F}(\mathrm{x}, \mathrm{Y})=\frac{2 x-y}{10},(\mathrm{x}, \mathrm{y}) \in \mathrm{X} \times \mathrm{X}$ and $g: \mathrm{X} \rightarrow \mathrm{X}$ by $g(\mathrm{x})=\frac{x}{2}, \mathrm{x} \in \mathrm{X}$.

Clearly, $F$ has the mixed g-monotone property on $X$ and the pair $(F, g)$ is compatible. It is easy to observe that $\mathrm{F}$ is $(\alpha)$ - admissible with respect to $\mathrm{g}$. Next, we claim that $\mathrm{F}$ is $(\alpha, \psi)$ - weak contraction with respect to $\mathrm{g}$. Indeed, if $\alpha((x, y),(u, v))=0$, then the result is obvious. Suppose $\alpha((x, y),(u, v))=1$. Without loss of generality, assume that $\mathrm{gx} \geq \mathrm{gu}$ and $\mathrm{gy} \leq \mathrm{gv}$ so that, $\mathrm{x} \geq \mathrm{u}$ and $\mathrm{y} \leq \mathrm{v}$. Then, we have that

$$
\begin{gathered}
\alpha((x, y),(u, v))\left(\frac{\mathrm{d}(F(x, y), F(u, v))+\mathrm{d}(F(y, x), F(v, u))}{2}\right) \\
\quad=\frac{\mathrm{d}(F(x, y), F(u, v))+\mathrm{d}(F(y, x), F(v, u))}{2} \\
\quad=\frac{1}{20}|2(x-u)-(y-v)|+\frac{1}{20}|2(y-v)-(x-u)| \\
\quad \leq \frac{3}{5}\left(\frac{\left|\frac{x}{2}-\frac{u}{2}\right|+\left|\frac{y}{2}-\frac{v}{2}\right|}{2}\right)=\psi\left(\frac{d(g x, g u)+d(g y, g v)}{2}\right) .
\end{gathered}
$$

Also, $x_{0}=-1$ and $y_{0}=1$ are two points in X such that $g\left(x_{0}\right) \leq \mathrm{F}\left(x_{0}, y_{0}\right)$ and $g\left(y_{0}\right) \geq \mathrm{F}\left(y_{0}, x_{0}\right)$.

Hence, all the conditions of Theorem 2.1 are satisfied. Indeed, the point $(0,0)$ is the coupled coincidence point of $\mathrm{F}$ and $\mathrm{g}$.

Next, we relax the assumption of the compatibility of the pair $(F, g)$ of mappings and replace the continuity assumption of the mapping $\mathrm{F}$ by an alternative condition imposed on the convergent sequences in the space $X$. We need the following definition.

Definition 2.1. Let $(X, \leq)$ be a partially ordered set and suppose there exists a metric $d$ on $X$. Consider the function $\alpha: X^{2} \times X^{2} \rightarrow[0,+\infty)$. We say that $(X, d, \leq)$ is $\alpha$-regular, if for each convergent sequences $\left(x_{n}\right)$ and $\left(y_{n}\right)$ in $X$ with

$$
\alpha\left(\left(x_{n}, y_{n}\right),\left(x_{n+1}, y_{n+1}\right)\right) \geq 1
$$

for all $\mathrm{n} \in \mathrm{N}$ and $\lim _{n \rightarrow \infty} x_{n}=\mathrm{x} \in \mathrm{X}$ and $\lim _{n \rightarrow \infty} y_{n}=\mathrm{y} \in \mathrm{X}$, then

$$
\alpha\left(\left(x_{n}, y_{n}\right),(x, y)\right) \geq 1,
$$

and the pairs $\left(x_{n}, y_{n}\right)$ and $(x, y)$ are comparable with respect to the ordering in $\mathrm{X} \times \mathrm{X}$.

Theorem 2.2. Let $(X, \leq)$ be a partially ordered set and there exists a metric $d$ on $X$. Let $F: X \times X \rightarrow X$ and $\mathrm{g}: \mathrm{X} \rightarrow \mathrm{X}$ be mappings such that $\mathrm{F}$ has the mixed g-monotone property. Assume that there exist two functions $\alpha: X^{2} \times X^{2} \rightarrow[0,+\infty)$ and $\psi \in \Psi$ such that $\mathrm{F}$ is $(\alpha, \psi)$ - weak contraction with respect to $g$. Suppose that 
(vi) hypotheses (i), (ii), (iii) of Theorem 2.1 hold and the range space $(g(X), d)$ is complete;

(vii) $\quad(\mathrm{X}, \mathrm{d}, \leq)$ is $\alpha$-regular.

If in hypotheses (ii), the elements $x_{0}, y_{0} \in \mathrm{X}$ be such that $\mathrm{g} x_{0} \leq \mathrm{F}\left(x_{0}, y_{0}\right)$ and $\mathrm{g} y_{0} \geq \mathrm{F}\left(y_{0}, x_{0}\right)$. Then $\mathrm{F}$ and $\mathrm{g}$ have a coupled coincidence point in $\mathrm{X}$; that is, there exist $\mathrm{x}, \mathrm{y} \in \mathrm{X}$ such that

$$
F(x, y)=g(x) \text { and } F(y, x)=g(y)
$$

Proof. Proceeding along the same lines as in the proof of Theorem 2.1, we know that $\left(g x_{n}\right)$ and $\left(g y_{n}\right)$ are Cauchy sequences in the complete metric space $(g(X), d)$. Then there exist $\mathrm{x}, \mathrm{y} \in \mathrm{X}$ such that $\mathrm{gx}_{\mathrm{n}} \rightarrow \mathrm{gx}$ and $\mathrm{gy}_{\mathrm{n}} \rightarrow \mathrm{gy}$; that is,

$$
\lim _{n \rightarrow \infty} d\left(g x_{n}, g x\right)=0 \quad \text { and } \quad \lim _{n \rightarrow \infty} d\left(g y_{n}, g y\right)=0 .
$$

On the other hand, from (2.3) and hypotheses (vii), we obtain for all $n \in N$, that

$$
\alpha\left(\left(g x_{n}, g y_{n}\right),(g x, g y)\right) \geq 1,
$$

and the pairs $\left(g x_{n}, g x\right)$ and $\left(g y_{n}, g y\right)$ are comparable. Using the triangle inequality and (2.9), we obtain

$$
\begin{aligned}
& \frac{d(F(x, y), g x)+d(F(y, x), g y)}{2} \\
& \quad \leq \frac{d\left(F(x, y), F\left(x_{n}, y_{n}\right)\right)+d\left(F(y, x), F\left(y_{n}, x_{n}\right)\right)}{2}+\frac{d\left(F\left(x_{n}, y_{n}\right), g x\right)+d\left(F\left(y_{n}, x_{n}\right), g y\right)}{2} \\
& =\frac{d\left(F(x, y), F\left(x_{n}, y_{n}\right)\right)+d\left(F(y, x), F\left(y_{n}, x_{n}\right)\right)}{2}+\frac{d\left(g x_{n+1}, g x\right)+d\left(g y_{n+1}, g y\right)}{2} \\
& \leq \alpha\left(\left(g x_{n}, g y_{n}\right),(g x, g y)\right)\left(\frac{d\left(F(x, y), F\left(x_{n}, y_{n}\right)\right)+d\left(F(y, x), F\left(y_{n}, x_{n}\right)\right)}{2}\right) \\
& \quad+\left(\frac{d\left(g x_{n+1}, g x\right)+d\left(g y_{n+1}, g y\right)}{2}\right) \\
& \leq \psi\left(\frac{d\left(g x_{n}, g x\right)+d\left(g y_{n}, g y\right)}{2}\right)+\left(\frac{d\left(g x_{n+1}, g x\right)+d\left(g y_{n+1}, g y\right)}{2}\right) .
\end{aligned}
$$

Then by the properties of $\psi$, we can easily obtain that

$\mathrm{d}(F(x, y), g x)=0$ and $\mathrm{d}(F(y, x), g y)=0$.

Therefore, $F(x, y)=g x$ and $F(y, x)=g y$.

Example 2.2. Let $X=[0,1]$. Then $(X, \leq)$ is a partially ordered set with the natural ordering of real numbers.

Let $d(x, y)=|x-y|$ for $x, y \in X$.

Let $\mathrm{g}: \mathrm{X} \rightarrow \mathrm{X}$ be defined as

$$
g(\mathrm{x})=x^{2}, \text { for all } \mathrm{x} \in \mathrm{X} .
$$

Let $F: X \times X \rightarrow X$ be defined as 


$$
\mathrm{F}(\mathrm{x}, \mathrm{y})=\left\{\begin{array}{cc}
\frac{x^{2}-y^{2}}{4}, & \text { if } x, y \in[0,1], x \geq y, \\
0, & \text { if } x<y .
\end{array}\right.
$$

Let $\left\{x_{n}\right\}$ and $\left\{y_{n}\right\}$ be two sequences in $\mathrm{X}$ such that

$$
\begin{aligned}
& \lim _{n \rightarrow \infty} F\left(x_{n}, y_{n}\right)=\mathrm{a}, \lim _{n \rightarrow \infty} \mathrm{g}\left(\mathrm{x}_{\mathrm{n}}\right)=\mathrm{a}, \\
& \lim _{n \rightarrow \infty} F\left(y_{n}, x_{n}\right)=\mathrm{b} \text { and } \lim _{n \rightarrow \infty} \mathrm{g}\left(\mathrm{y}_{\mathrm{n}}\right)=\mathrm{b}
\end{aligned}
$$

Now, for all $n \geq 0$,

$$
\begin{aligned}
& g\left(x_{n}\right)=x_{n}^{2}, g\left(y_{n}\right)=y_{n}^{2}, \\
& \mathrm{~F}\left(x_{n}, y_{n}\right)=\left\{\begin{array}{cc}
\frac{x_{n}^{2}-y_{n}^{2}}{4}, & \text { if } x, y \in[0,1], x_{n} \geq y_{n}, \\
0, & \text { if } x_{n}<y_{n},
\end{array}\right.
\end{aligned}
$$

and

$$
\mathrm{F}\left(y_{n}, x_{n}\right)=\left\{\begin{array}{cc}
\frac{y_{n}^{2}-x_{n}^{2}}{4}, & \text { if } x, y \in[0,1], y_{n} \geq x_{n}, \\
0, & \text { if } y_{n}<x_{n} .
\end{array}\right.
$$

Obviously, $\mathrm{a}=0$ and $\mathrm{b}=0$.

Then it follows that,

$$
\mathrm{d}\left(g\left(\mathrm{~F}\left(x_{n}, y_{n}\right), \mathrm{F}\left(g x_{n}, g y_{n}\right)\right) \rightarrow 0 \text { as } \mathrm{n} \rightarrow \infty,\right.
$$

and

$$
\mathrm{d}\left(g\left(\mathrm{~F}\left(y_{n}, x_{n}\right), \mathrm{F}\left(g y_{n}, g x_{n}\right)\right) \rightarrow 0 \text { as } \mathrm{n} \rightarrow \infty .\right.
$$

Hence, the mappings $\mathrm{F}$ and $g$ are compatible in $\mathrm{X}$. Clearly, $\mathrm{F}$ obeys the mixed $g$-monotone property. Also, $\mathrm{F}(\mathrm{X} \times \mathrm{X}) \subseteq g(\mathrm{X})$ and the range space $(\mathrm{g}(\mathrm{X})$, d) is complete.

Define the function $\alpha: X^{2} \times X^{2} \rightarrow[0,+\infty)$ by

$$
\alpha((x, y),(u, v))=\left\{\begin{array}{l}
1, \text { if } x \geq u, y \leq v, \text { or } x \leq u, y \geq v \\
0, \text { otherwise. }
\end{array}\right.
$$

Then, the space $(\mathrm{X}, \mathrm{d}, \leq)$ is $\alpha$-regular.

Let us define $:[0,+\infty) \rightarrow[0,+\infty)$ by $\psi(t)=\frac{t}{3}$, for $t \in[0, \infty)$.

Also, $x_{0}=0$ and $y_{0}=\mathrm{c}(>0)$ are two points in X such that $g\left(x_{0}\right)=g(0)=0=\mathrm{F}(0, \mathrm{c})=\mathrm{F}\left(x_{0}, y_{0}\right)$ and $g\left(y_{0}\right)=g(\mathrm{c})=c^{2} \geq \frac{c^{2}}{4}=\mathrm{F}(\mathrm{c}, 0)=\mathrm{F}\left(y_{0}, x_{0}\right)$. It is easy to observe that $\mathrm{F}$ is $(\alpha)$ - admissible with respect to $\mathrm{g}$.

Next, we claim that $\mathrm{F}$ is $(\alpha, \psi)$ - weak contraction with respect to g. Indeed, if $\alpha((x, y),(u, v))=0$, then the result is obvious. Suppose $\alpha((x, y),(u, v))=1$. 
We take $\mathrm{x}, \mathrm{y}, \mathrm{u}, \mathrm{v} \in \mathrm{X}$, such that $g \mathrm{x} \geq g \mathrm{u}$ and $g \mathrm{y} \leq g \mathrm{v}$; that is, $x^{2} \geq u^{2}$ and $y^{2} \leq v^{2}$. We discuss the following cases:

Case 1: $x \geq y, u \geq v$.

$$
\text { Then } \begin{aligned}
\alpha & ((x, y),(u, v))\left(\frac{\mathrm{d}(F(x, y), F(u, v))+\mathrm{d}(F(y, x), F(v, u))}{2}\right) \\
& =\frac{\mathrm{d}(F(x, y), F(u, v))+\mathrm{d}(F(y, x), F(v, u))}{2}=\frac{\mathrm{d}(\mathrm{F}(\mathrm{x}, \mathrm{y}), \mathrm{F}(\mathrm{u}, \mathrm{v}))+\mathrm{d}(0,0)}{2}=\frac{1}{2} \mathrm{~d}\left(\frac{x^{2}-y^{2}}{4}, \frac{u^{2}-v^{2}}{4}\right) \\
& =\frac{1}{2}\left|\frac{x^{2}-y^{2}}{4}-\frac{u^{2}-v^{2}}{4}\right|=\frac{1}{2}\left|\frac{\left(x^{2}-u^{2}\right)+\left(v^{2}-y^{2}\right)}{4}\right|=\frac{1}{4}\left\{\frac{\left(x^{2}-u^{2}\right)+\left(v^{2}-y^{2}\right)}{2}\right\} \\
& \leq \frac{1}{3}\left\{\frac{\left(x^{2}-u^{2}\right)+\left(v^{2}-y^{2}\right)}{2}\right\}=\frac{1}{3}\left\{\frac{d(g x, g u)+d(g v, g y)}{2}\right\}=\psi\left(\frac{d(g x, g u)+d(g v, g y)}{2}\right) .
\end{aligned}
$$

Case 2: $x \geq y, u<v$.

$$
\begin{aligned}
& \text { Then } \alpha((x, y),(u, v))\left(\frac{\mathrm{d}(F(x, y), F(u, v))+\mathrm{d}(F(y, x), F(v, u))}{2}\right) \\
& =\frac{\mathrm{d}(F(x, y), F(u, v))+\mathrm{d}(F(y, x), F(v, u))}{2}=\frac{1}{2}\left\{\mathrm{~d}\left(\frac{x^{2}-y^{2}}{4}, 0\right)+\mathrm{d}\left(0, \frac{v^{2}-u^{2}}{4}\right)\right\} \\
& \quad=\frac{1}{2}\left\{\left(\frac{x^{2}-y^{2}}{4}\right)+\left(\frac{v^{2}-u^{2}}{4}\right)\right\}=\frac{1}{2}\left\{\left(\frac{x^{2}-u^{2}}{4}\right)+\left(\frac{v^{2}-y^{2}}{4}\right)\right\} \\
& \quad \leq \frac{1}{3}\left\{\frac{\left(x^{2}-u^{2}\right)+\left(v^{2}-y^{2}\right)}{2}\right\}=\frac{1}{3}\left\{\frac{d(g x, g u)+d(g v, g y)}{2}\right\}=\psi\left(\frac{d(g x, g u)+d(g v, g y)}{2}\right) .
\end{aligned}
$$

Case 3: $x<y, u \geq v$.

Then $\alpha((x, y),(u, v))\left(\frac{\mathrm{d}(F(x, y), F(u, v))+\mathrm{d}(F(y, x), F(v, u))}{2}\right)$

$$
\begin{aligned}
& =\frac{\mathrm{d}(\mathrm{F}(\mathrm{x}, \mathrm{y}), \mathrm{F}(\mathrm{u}, \mathrm{v}))+\mathrm{d}(\mathrm{F}(\mathrm{y}, \mathrm{x}), \mathrm{F}(\mathrm{v}, \mathrm{u}))}{2}=\frac{1}{2}\left\{\mathrm{~d}\left(0, \frac{u^{2}-v^{2}}{4}\right)+\mathrm{d}\left(\frac{y^{2}-x^{2}}{4}, 0\right)\right\} \\
& =\frac{1}{2}\left\{\left(\frac{u^{2}-v^{2}}{4}\right)+\left(\frac{y^{2}-x^{2}}{4}\right)\right\}=\frac{1}{2}\left\{\frac{-\left(x^{2}-u^{2}\right)-\left(v^{2}-y^{2}\right)}{4}\right\} \leq \frac{1}{4}\left\{\frac{\left(x^{2}-u^{2}\right)+\left(v^{2}-y^{2}\right)}{2}\right\} \\
& \leq \frac{1}{3}\left\{\frac{\left(x^{2}-u^{2}\right)+\left(v^{2}-y^{2}\right)}{2}\right\}=\frac{1}{3}\left\{\frac{d(g x, g u)+d(g v, g y)}{2}\right\}=\psi\left(\frac{d(g x, g u)+d(g v, g y)}{2}\right) .
\end{aligned}
$$

Case 4: $x<y, u<v$.

Then $\alpha((x, y),(u, v))\left(\frac{\mathrm{d}(F(x, y), F(u, v))+\mathrm{d}(F(y, x), F(v, u))}{2}\right)$

$$
\begin{aligned}
& =\frac{\mathrm{d}(\mathrm{F}(\mathrm{x}, \mathrm{y}), \mathrm{F}(\mathrm{u}, \mathrm{v}))+\mathrm{d}(\mathrm{F}(\mathrm{y}, \mathrm{x}), \mathrm{F}(\mathrm{v}, \mathrm{u}))}{2}=\frac{\mathrm{d}(0,0)+\mathrm{d}(\mathrm{F}(\mathrm{y}, \mathrm{x}), \mathrm{F}(\mathrm{v}, \mathrm{u}))}{2}=\frac{1}{2} \mathrm{~d}\left(\frac{y^{2}-x^{2}}{4}, \frac{v^{2}-u^{2}}{4}\right) \\
= & \frac{1}{2}\left|\frac{y^{2}-x^{2}}{4}-\frac{v^{2}-u^{2}}{4}\right|=\frac{1}{2}\left|\frac{-\left(x^{2}-u^{2}\right)-\left(v^{2}-y^{2}\right)}{4}\right|=\frac{1}{2}\left\{\frac{\left|\left(x^{2}-u^{2}\right)+\left(v^{2}-y^{2}\right)\right|}{4}\right\}=\frac{1}{2}\left\{\frac{\left(x^{2}-u^{2}\right)+\left(v^{2}-y^{2}\right)}{4}\right\} \\
\leq & \frac{1}{3}\left\{\frac{\left(x^{2}-u^{2}\right)+\left(v^{2}-y^{2}\right)}{2}\right\}=\frac{1}{3}\left\{\frac{d(g x, g u)+d(g v, g y)}{2}\right\}=\psi\left(\frac{d(g x, g u)+d(g v, g y)}{2}\right) .
\end{aligned}
$$

Hence, the mapping $\mathrm{F}$ is $(\alpha, \psi)$ - weak contraction with respect to $\mathrm{g}$. 
Thus all the conditions of Theorem 2.2 are satisfied and it can be easily seen that $(0,0)$ is the required coupled coincidence point of $\mathrm{F}$ and $g$ in $\mathrm{X}$.

Now, putting $g=I_{X}$ (the identity map on $X$ ) in the previous results, we obtain the following result.

Theorem 2.3. Let $(X, \leq)$ be a partially ordered set and there exists a metric $d$ on $X$ such that $(X, d)$ is a complete metric space. Let $\mathrm{F}: \mathrm{X} \times \mathrm{X} \rightarrow \mathrm{X}$ be a mapping having the mixed monotone property. Suppose there exist two functions $\alpha: X^{2} \times X^{2} \rightarrow[0,+\infty)$ and $\psi \in \Psi$ such that $\mathrm{F}$ is $(\alpha, \psi)$ - weak contraction.

Also suppose that

(viii) $\mathrm{F}$ is $(\alpha)$-admissible;

(ix) there exist $x_{0}, y_{0} \in \mathrm{X}$ such that

$$
\alpha\left(\left(x_{0}, y_{0}\right),\left(\mathrm{F}\left(x_{0}, y_{0}\right), \mathrm{F}\left(y_{0}, x_{0}\right)\right)\right) \geq 1
$$

(x) the mapping $\mathrm{F}$ is continuous or $(\mathrm{X}, \mathrm{d}, \leq)$ is $\alpha$-regular.

If in the hypotheses (ix), the elements $x_{0}, y_{0} \in \mathrm{X}$ be such that $x_{0} \leq \mathrm{F}\left(x_{0}, y_{0}\right)$ and $y_{0} \geq \mathrm{F}\left(y_{0}, x_{0}\right)$, then $\mathrm{F}$ has a coupled fixed point in $X$; that is, there exist, $x, y \in X$ such that

$$
F(x, y)=x \text { and } F(y, x)=y \text {. }
$$

Remark 2.1. If in Theorem 2.1 (and in Theorem 2.2, respectively), hypotheses (ii) is replaced by the following hypotheses:

(xi) there exist $x_{0}, y_{0} \in \mathrm{X}$ such that $\alpha\left(\left(g y_{0}, g x_{0}\right),\left(\mathrm{F}\left(y_{0}, x_{0}\right), \mathrm{F}\left(x_{0}, y_{0}\right)\right)\right) \geq 1$ with $g x_{0} \geq \mathrm{F}\left(x_{0}, y_{0}\right)$ and $g y_{0} \leq F\left(y_{0}, x_{0}\right)$, then we also get the existence of some $x, y \in X$ such that $F(x, y)=g(x)$ and $F(y, x)=g(y)$.

And if in Theorem 2.3, hypotheses (ix) is replaced by the following hypotheses:

(xii) there exist $x_{0}, y_{0} \in \mathrm{X}$ such that $\alpha\left(\left(y_{0}, x_{0}\right),\left(\mathrm{F}\left(y_{0}, x_{0}\right), \mathrm{F}\left(x_{0}, y_{0}\right)\right)\right) \geq 1$ with $x_{0} \geq \mathrm{F}\left(x_{0}, y_{0}\right)$ and $y_{0} \leq \mathrm{F}\left(y_{0}, x_{0}\right)$, then we also get the existence of some $\mathrm{x}, \mathrm{y} \in \mathrm{X}$ such that $\mathrm{F}(\mathrm{x}, \mathrm{y})=\mathrm{x}$ and $\mathrm{F}(\mathrm{y}, \mathrm{x})$ $=\mathrm{y}$.

Remark 2.2. Theorem 2.3, along with Remark 2.1 improves the main results of Karapinar et al. [41, Theorems 2.1 and 2.2]. Note that, we require only one of the conditions:

(a) $\alpha\left(\left(x_{0}, y_{0}\right),\left(\mathrm{F}\left(x_{0}, y_{0}\right), \mathrm{F}\left(y_{0}, x_{0}\right)\right)\right) \geq 1 \quad$ or $\quad$ (b) $\quad \alpha\left(\left(y_{0}, x_{0}\right),\left(\mathrm{F}\left(y_{0}, x_{0}\right), \mathrm{F}\left(x_{0}, y_{0}\right)\right)\right) \geq 1$ to produce a coupled fixed point of the mapping $\mathrm{F}$ rather than assuming both the conditions (a) and (b) as in the results of Karapinar et al. [41, Theorems 2.1 and 2.2] and in the results of Mursaleen et al. [40, Theorems 3.4 and 3.5]

The following example illustrates that Theorem 2.3 is more general than the main result in [19, Theorem 2.1] and [40, Theorem 3.4].

Example 2.3. Let $X=\mathbb{R}$. Then $(X, \leq)$ is a partially ordered set with the natural ordering of real numbers. Let $d: X \times X \rightarrow R^{+}$be defined by

$$
d(x, y)=|x-y| \text { for } x, y \in X
$$


Then $(X, d)$ is a complete metric space.

Consider the mapping $\alpha: X^{2} \times X^{2} \rightarrow[0,+\infty)$ defined as

$$
\alpha((x, y),(u, v))=\left\{\begin{array}{l}
1, \text { if } x \geq u, y \leq v, \text { or } x \leq u, y \geq v \\
0, \text { otherwise. }
\end{array}\right.
$$

Let us define $:[0,+\infty) \rightarrow[0,+\infty)$ by $\psi(t)=\frac{7}{10} t$, for $t \in[0, \infty)$.

Define $\mathrm{F}: \mathrm{X} \times \mathrm{X} \rightarrow \mathrm{X}$ by $\mathrm{F}(\mathrm{X}, \mathrm{y})=\frac{6 x-y}{10},(\mathrm{x}, \mathrm{y}) \in \mathrm{X} \times \mathrm{X}$.

Then, $\mathrm{F}$ is continuous and has the mixed monotone property. It is easy to observe that $\mathrm{F}$ is $(\alpha)-$ admissible. Also, $\mathrm{F}$ is $(\alpha, \psi)$ - weak contraction but does not satisfy either of the condition (1.2) or the condition (1.6).

Indeed, assume there exists some $k \in[0,1)$ such that the condition (1.2) holds. Then, we must have

$$
\left|\frac{6 x-y}{10}-\frac{6 u-v}{10}\right| \leq \frac{k}{2}\{|x-u|+|y-v|\}, \mathrm{x} \geq \mathrm{u} \text { and } \mathrm{y} \leq \mathrm{v},
$$

by which, for $y=v$, we get

$$
\frac{3}{5}|x-u| \leq \frac{k}{2}|x-u|, \mathrm{x} \geq \mathrm{u},
$$

which for $x>\mathrm{u}$ implies $\mathrm{k}>1$, a contradiction, since $\mathrm{k} \in[0,1)$. Hence, $\mathrm{F}$ does not satisfy condition (1.2).

Further, condition (1.6) is also not satisfied. Assume, to the contrary, that there exists some $\psi \in \Psi$ such that condition (1.6) holds. Then we must have

$$
\alpha((x, y),(u, v)) \mathrm{d}(F(x, y), F(u, v)) \leq \psi\left(\frac{d(x, u)+d(y, v)}{2}\right)
$$

holds for all $\mathrm{x} \geq \mathrm{u}$ and $\mathrm{y} \leq \mathrm{v}$. Let us take $\mathrm{x} \neq \mathrm{u}, \mathrm{y}=\mathrm{v}$ in the previous inequality. Hence, $\mathrm{t}=|x-u|>0$ and the previous inequality turns into

$$
\frac{3}{5} t=\frac{3|x-u|}{5} \leq \psi\left(\frac{|x-u|}{2}\right)=\psi\left(\frac{t}{2}\right)
$$

since $\psi(\mathrm{t})<\mathrm{t}$ for $\mathrm{t}>0$, we have $\frac{3}{5} t \leq \psi\left(\frac{t}{2}\right)<\frac{t}{2}$, a contradiction. Hence, $\mathrm{F}$ does not satisfy (1.6).

Next we prove that $\mathrm{F}$ is $(\alpha, \psi)$ - weak contraction. Indeed, if $\alpha((x, y),(u, v))=0$, then the result is obvious. Suppose $\alpha((x, y),(u, v))=1$. Without loss of generality, assume that $\mathrm{x} \geq \mathrm{u}$ and $\mathrm{y} \leq \mathrm{v}$. Then, we have that

$$
\begin{aligned}
& \alpha((x, y),(u, v))\left(\frac{\mathrm{d}(F(x, y), F(u, v))+\mathrm{d}(F(y, x), F(v, u))}{2}\right) \\
= & \frac{\mathrm{d}(F(x, y), F(u, v))+\mathrm{d}(F(y, x), F(v, u))}{2} \\
= & \frac{1}{20}|6(x-u)-(y-v)|+\frac{1}{20}|6(y-v)-(x-u)|
\end{aligned}
$$




$$
\leq \frac{7}{10}\left(\frac{|x-u|+|y-v|}{2}\right)=\psi\left(\frac{d(x, u)+d(y, v)}{2}\right) .
$$

Also, $x_{0}=-1$ and $y_{0}=1$ are two points in $\mathrm{X}$ such that $x_{0} \leq \mathrm{F}\left(x_{0}, y_{0}\right)$ and $y_{0} \geq \mathrm{F}\left(y_{0}, x_{0}\right)$.

So by our Theorem 2.3 we obtain that $F$ has a (unique) coupled fixed point $(0,0)$ but either Theorem 2.1 in [19] or Theorem 3.4 in [40] cannot be applied to $F$ in this example.

Theorem 2.4. Let $(X, \leq)$ be partially ordered set and let $d$ be a metric on $X$ such that $(X, d)$ is complete. Let $\mathrm{F}: \mathrm{X} X \mathrm{X} \rightarrow \mathrm{X}$ and $\mathrm{g}: \mathrm{X} \rightarrow \mathrm{X}$ be two mappings such that $\mathrm{F}$ satisfy the mixed g-monotone property. Suppose that there exists a function $\psi \in \Psi$ such that

$$
\frac{\mathrm{d}(F(x, y), F(u, v))+\mathrm{d}(F(y, x), F(v, u))}{2} \leq \psi\left(\frac{d(g x, g u)+d(g y, g v)}{2}\right),
$$

for all $\mathrm{x}, \mathrm{y}, \mathrm{u}, \mathrm{v} \in \mathrm{X}$ with gx $\geq \mathrm{gu}$ and gy $\leq \mathrm{gv}$ (or gx $\leq$ gu and gy $\geq \mathrm{gv}$ ). Suppose also that the following conditions hold:

(xiii) the pair $(F, g)$ is compatible;

(xiv) both the mappings $F$ and $g$ are continuous;

(xv) $\quad \mathrm{F}(\mathrm{X} \times \mathrm{X}) \subseteq \mathrm{g}(\mathrm{X})$;

(xvi) there exist $x_{0}, y_{0} \in \mathrm{X}$ such that $\mathrm{g} x_{0} \leq \mathrm{F}\left(x_{0}, y_{0}\right)$ and $\mathrm{g} y_{0} \geq \mathrm{F}\left(y_{0}, x_{0}\right)$.

Then the mappings $F$ and $g$ have a coupled coincidence point in $X$; that is, there exist $x, y \in X$ such that

$$
F(x, y)=g(x) \text { and } F(y, x)=g(y)
$$

Proof. Define the mapping $\alpha: X^{2} \times X^{2} \rightarrow[0,+\infty)$ by

$$
\alpha((x, y),(u, v))=\left\{\begin{array}{l}
1, \text { if } x \geq u, y \leq v, \text { or } x \leq u, y \geq v \\
0, \text { otherwise }
\end{array}\right.
$$

so that using assumption (xiv), we have $\alpha\left(\left(g x_{0}, g y_{0}\right),\left(\mathrm{F}\left(x_{0}, y_{0}\right), \mathrm{F}\left(y_{0}, x_{0}\right)\right)\right) \geq 1$. Further, for all $(x, y),(u, v) \in \mathrm{X} \times \mathrm{X}$, by the mixed g-monotone property of $\mathrm{F}$, we have

$$
\begin{aligned}
& \alpha((g x, g y),(g u, g v)) \geq 1 \Rightarrow g x \geq g u \text { and } g y \leq g v \quad \text { or } g x \leq g u \text { and } g y \geq g v \\
& \Rightarrow F(x, y) \geq F(u, v) \text { and } F(y, x) \leq F(v, u) \text { or } F(y, x) \geq F(v, u) \text { and } F(x, y) \leq F(u, v) \\
& \Rightarrow \alpha((F(x, y), F(y, x)),(F(u, v), F(v, u))) \geq 1 .
\end{aligned}
$$

Therefore, $\mathrm{F}$ is $\alpha$-admissible with respect to $\mathrm{g}$. Moreover, by (2.10) and (2.11), $\mathrm{F}$ is $(\alpha, \psi)$ - weak contraction with respect to $\mathrm{g}$. Then, Theorem 2.1 yields the existence of a coupled coincidence point of the mappings $\mathrm{F}$ and $\mathrm{g}$.

Remark 2.3. Result analogous to Theorem 2.4 can be obtained from Theorem 2.2 for $\alpha$-regular space.

Remark 2.4.(i) Theorem 2.4 along with Remark 2.3 provides a generalization of the recent result in [38, Corollary 2.3]. By defining $\psi(t)=k t, k \in[0,1)$ in Theorem 2.4, we obtain the contraction (1.4). 
(ii) For $\mathrm{g}=\mathrm{I}_{\mathrm{X}}$ (the identity mapping on $\mathrm{X}$ ), Theorem 2.4 along with Remark 2.3 provides a generalization of the recent result in [20, Theorem 3]. By defining $\psi(t)=k t, k \in[0,1)$ in Theorem 2.4, we obtain the contraction (1.3).

\section{Existence and Uniqueness of the Coupled Fixed Points}

Now, in order to prove the existence and uniqueness of the coupled common fixed point for our main results, we need the following Lemma.

Lemma 3.1. Let $F: X \times X \rightarrow X$ and $g: X \rightarrow X$ be compatible maps and there exists an element $(x, y) \in$ $\mathrm{X} \times \mathrm{X}$, such that $g \mathrm{x}=\mathrm{F}(\mathrm{x}, \mathrm{y})$ and $g \mathrm{y}=\mathrm{F}(\mathrm{y}, \mathrm{x})$, then $g \mathrm{~F}(\mathrm{x}, \mathrm{y})=\mathrm{F}(g \mathrm{x}, g \mathrm{y})$ and $g \mathrm{~F}(\mathrm{y}, \mathrm{x})=\mathrm{F}(g \mathrm{y}, g \mathrm{x})$.

Proof. Since the pair $(\mathrm{F}, g)$ is compatible, it follows that

$$
\begin{gathered}
\lim _{n \rightarrow \infty} d\left(g F\left(x_{n}, y_{n}\right), F\left(g\left(x_{n}\right), g\left(y_{n}\right)\right)\right)=0, \\
\lim _{n \rightarrow \infty} d\left(g F\left(y_{n}, x_{n}\right), F\left(g\left(y_{n}\right), g\left(x_{n}\right)\right)\right)=0,
\end{gathered}
$$

whenever $\left\{x_{n}\right\}$ and $\left\{y_{n}\right\}$ are sequences in $X$, such that

$\lim _{n \rightarrow \infty} F\left(x_{n}, y_{n}\right)=\lim _{n \rightarrow \infty} g\left(x_{n}\right)=\mathrm{a}, \lim _{n \rightarrow \infty} F\left(y_{n}, x_{n}\right)=\lim _{n \rightarrow \infty} g\left(y_{n}\right)=\mathrm{b}$ for some a, b in X.

Taking $x_{n}=\mathrm{x}, y_{n}=\mathrm{y}$ for all $\mathrm{n} \in \mathbb{N}$ and using $g \mathrm{x}=\mathrm{F}(\mathrm{x}, \mathrm{y}), g \mathrm{y}=\mathrm{F}(\mathrm{y}, \mathrm{x})$, it follows that

$$
\mathrm{d}(g \mathrm{~F}(\mathrm{x}, \mathrm{y}), \mathrm{F}(g \mathrm{x}, g \mathrm{y}))=0 \text { and } \mathrm{d}(g \mathrm{~F}(\mathrm{y}, \mathrm{x}), \mathrm{F}(g \mathrm{y}, g \mathrm{x}))=0 \text {. }
$$

Hence, $g \mathrm{~F}(\mathrm{x}, \mathrm{y})=\mathrm{F}(g \mathrm{x}, g \mathrm{y})$ and $g \mathrm{~F}(\mathrm{y}, \mathrm{x})=\mathrm{F}(g \mathrm{y}, g \mathrm{x})$.

Theorem 3.1. In addition to the hypotheses of Theorem 2.1, suppose that for every $(x, y),\left(x^{*}, y^{*}\right) \in X$ $\times X$, there exists $(u, v) \in X \times X$ such that

$$
\alpha((g x, g y),(g u, g v)) \geq 1 \quad \text { and } \alpha\left(\left(g x^{*}, g y^{*}\right),(g u, g v)\right) \geq 1 \text {, }
$$

and also assume that (gu, gv) is comparable to (gx, gy) and $\left(\mathrm{gx}^{*}, \mathrm{gy}^{*}\right)$. Then $\mathrm{F}$ and $g$ have a unique coupled common fixed point; that is, there exists a unique $(\mathrm{x}, \mathrm{y}) \in \mathrm{X} \times \mathrm{X}$ such that $\mathrm{x}=g(\mathrm{x})=\mathrm{F}(\mathrm{x}, \mathrm{y})$ and $\mathrm{y}=g(\mathrm{y})=\mathrm{F}(\mathrm{y}, \mathrm{x})$.

Proof. By Theorem 2.1, the set of coupled coincidences is non-empty. In order to prove the theorem, we shall first show that if $(x, y)$ and $\left(x^{*}, y^{*}\right)$ are coupled coincidence points; that is, if $g x=$ $\mathrm{F}(\mathrm{x}, \mathrm{y}), g \mathrm{y}=\mathrm{F}(\mathrm{y}, \mathrm{x})$ and $g \mathrm{x}^{*}=\mathrm{F}\left(\mathrm{x}^{*}, \mathrm{y}^{*}\right), g \mathrm{y}^{*}=\mathrm{F}\left(\mathrm{y}^{*}, \mathrm{x}^{*}\right)$, then

$$
g \mathrm{x}=g \mathrm{x}^{*} \text { and } g \mathrm{y}=g \mathrm{y}^{*} \text {. }
$$

By assumption, there exists $(u, v) \in X \times X$ such that

$$
\alpha((g x, g y),(g u, g v)) \geq 1 \quad \text { and } \quad \alpha\left(\left(g x^{*}, g y^{*}\right),(g u, g v)\right) \geq 1,
$$

and (gu, gv) is comparable with (gx, gy) and (gx $\left.{ }^{*}, \mathrm{gy}^{*}\right)$. Put $u_{0}=\mathrm{u}, v_{0}=\mathrm{v}$ and choose $u_{1}, v_{1} \in \mathrm{X}$ so that $g u_{1}=\mathrm{F}\left(u_{0}, v_{0}\right), g v_{1}=\mathrm{F}\left(v_{0}, u_{0}\right)$.

Then, similarly as in the proof of Theorem (2.1), we can inductively define the sequences $\left\{g u_{n}\right\}$ and $\left\{g v_{n}\right\}$ such that $g u_{n+1}=\mathrm{F}\left(u_{n}, v_{n}\right)$ and $g v_{n+1}=\mathrm{F}\left(v_{n}, u_{n}\right)$. 
Further, set $x_{0}=\mathrm{x}, y_{0}=\mathrm{y}, x_{0}^{*}=\mathrm{x}^{*}, y_{0}^{*}=\mathrm{y}^{*}$ and, on the same way, define the sequences $\left\{g x_{n}\right\},\left\{g y_{n}\right\}$ and $\left\{g x_{n}^{*}\right\},\left\{g y_{n}^{*}\right\}$. Then it is easy to show that

$$
g x_{n+1}=\mathrm{F}\left(x_{n}, y_{n}\right), g y_{n+1}=\mathrm{F}\left(y_{n}, x_{n}\right)
$$

and

$$
g x_{n+1}^{*}=\mathrm{F}\left(x_{n}^{*}, y_{n}^{*}\right), g y_{n+1}^{*}=\mathrm{F}\left(y_{n}^{*}, x_{n}^{*}\right) \text { for all } \mathrm{n} \geq 0 .
$$

Since (gu, gv) is comparable with (gx, gy), we may assume (gx, gy) $\geq(\mathrm{gu}, \mathrm{gv})=\left(\mathrm{g} u_{0}, \mathrm{~g} v_{0}\right)$. By the proof of Theorem 2.1, we obtain inductively $(\mathrm{gx}, \mathrm{gy}) \geq\left(\mathrm{g} u_{n}, \mathrm{~g} v_{n}\right)$ for all $\mathrm{n} \geq 0$.

Since $\mathrm{F}$ is $(\alpha)$ - admissible with respect to $\mathrm{g}$, so from (3.2), we have

$$
\alpha((g x, g y),(g u, g v)) \geq 1 \Rightarrow \alpha((F(x, y), F(y, x)),(F(u, v), F(v, u))) \geq 1 .
$$

Since $u=u_{0}$ and $v=v_{0}$, we get

$$
\alpha((g x, g y),(g u, g v)) \geq 1 \Rightarrow \alpha\left((F(x, y), F(y, x)),\left(F\left(u_{0}, v_{0}\right), F\left(v_{0}, u_{0}\right)\right)\right) \geq 1 \text {. }
$$

Thus,

$$
\alpha((g x, g y),(g u, g v)) \geq 1 \Rightarrow \alpha\left((g x, g y),\left(g u_{1}, g v_{1}\right)\right) \geq 1 .
$$

Then, using mathematical induction, we obtain

$$
\alpha\left((g x, g y),\left(g u_{n}, g v_{n}\right)\right) \geq 1,
$$

for all $n \in N$. From (3.2) and (3.3), we get

$$
\begin{aligned}
\frac{d\left(g x, g u_{n+1}\right)+d\left(g y, g v_{n+1}\right)}{2} & =\frac{d\left(F(x, y), F\left(u_{n}, v_{n}\right)\right)+d\left(F(y, x), F\left(v_{n}, u_{n}\right)\right)}{2} \\
\leq & \alpha\left((g x, g y),\left(g u_{n}, g v_{n}\right)\right) \frac{d\left(F(x, y), F\left(u_{n}, v_{n}\right)\right)+d\left(F(y, x), F\left(v_{n}, u_{n}\right)\right)}{2} \\
\leq & \psi\left(\frac{d\left(g x, g u_{n}\right)+d\left(g y, g v_{n}\right)}{2}\right) .
\end{aligned}
$$

Thus,

$$
\frac{d\left(g x, g u_{n+1}\right)+d\left(g y, g v_{n+1}\right)}{2} \leq \psi^{n}\left(\frac{d\left(g x, g u_{0}\right)+d\left(g y, g v_{0}\right)}{2}\right),
$$

for each $n \geq 1$. Letting $n \rightarrow \infty$ in (3.4), we get

$$
\lim _{n \rightarrow \infty}\left[d\left(g x, g u_{n+1}\right)+d\left(g y, g v_{n+1}\right)\right]=0 .
$$

This implies

$$
\lim _{n \rightarrow \infty} d\left(g x, g u_{n+1}\right)=\lim _{n \rightarrow \infty} d\left(g y, g v_{n+1}\right)=0 .
$$

Similarly, we can show that

$$
\lim _{n \rightarrow \infty} d\left(g x^{*}, g u_{n+1}\right)=\lim _{n \rightarrow \infty} d\left(g y^{*}, g v_{n+1}\right)=0 .
$$


From (3.5) and (3.6), we conclude that $g x=g x^{*}$ and $g y=g y^{*}$. Thus, we proved (3.1).

Since $g \mathrm{x}=\mathrm{F}(\mathrm{x}, \mathrm{y}), g \mathrm{y}=\mathrm{F}(\mathrm{y}, \mathrm{x})$ and the pair $(\mathrm{F}, g)$ is compatible, then by Lemma 3.1, it follows that

$$
g g \mathrm{x}=g \mathrm{~F}(\mathrm{x}, \mathrm{y})=\mathrm{F}(g \mathrm{x}, g \mathrm{y}) \text { and } g g \mathrm{y}=g \mathrm{~F}(\mathrm{y}, \mathrm{x})=\mathrm{F}(g \mathrm{y}, g \mathrm{x}) \text {. }
$$

Denote $g x=z, g y=w$. Then by (3.7),

$$
g z=F(z, w) \text { and } g w=F(w, z) .
$$

Thus $(z, w)$ is a coupled coincidence point.

Then by (3.1) with $\mathrm{x}^{*}=\mathrm{z}_{\text {and }} \mathrm{y}^{*}=\mathrm{w}$, it follows that $g \mathrm{z}=g \mathrm{x}$ and $g \mathrm{w}=g \mathrm{y}$; that is,

$$
g \mathrm{z}=\mathrm{z}, g \mathrm{w}=\mathrm{w} .
$$

By (3.8) and (3.9),

$$
z=g z=F(z, w) \text { and } w=g w=F(w, z) .
$$

Therefore, $(z, w)$ is the coupled common fixed point of $F$ and $g$.

To prove the uniqueness, assume that $(p, q)$ is another coupled common fixed point of $F$ and $g$. Then by (3.1), we have $\mathrm{p}=g \mathrm{p}=g \mathrm{z}=\mathrm{z}$ and $\mathrm{q}=g \mathrm{q}=g \mathrm{w}=\mathrm{w}$.

Hence, the mappings $F$ and $g$ have a unique coupled common fixed point.

Theorem 3.2. In addition to the hypotheses of Theorem 2.3, suppose that for every $(x, y),\left(x^{*}, y^{*}\right) \in X$ $\times \mathrm{X}$, there exists $(\mathrm{u}, \mathrm{v}) \in \mathrm{X} \times \mathrm{X}$ such that

$$
\alpha((x, y),(u, v)) \geq 1 \quad \text { and } \alpha\left(\left(x^{*}, y^{*}\right),(u, v)\right) \geq 1,
$$

and also assume that $(u, v)$ is comparable to $(x, y)$ and $\left(x^{*}, y^{*}\right)$. Then $F$ has a unique coupled fixed point; that is, there exists a unique $(x, y) \in X \times X$ such that $x=F(x, y)$ and $y=F(y, x)$.

\section{Applications to Integral Equations}

As an application of the results proved in Sections 2 and 3, we study the existence of solutions for the following system of integral equations:

$$
\begin{aligned}
& x(t)=\int_{a}^{b}\left(K_{1}(t, s)+K_{2}(t, s)\right)(f(s, x(s))+g(s, y(s))) d s+h(t), \\
& y(t)=\int_{a}^{b}\left(K_{1}(t, s)+K_{2}(t, s)\right)(f(s, y(s))+g(s, x(s))) d s+h(t),
\end{aligned}
$$

$t \in I=[a, b]$.

Let $\Theta$ denote the class of functions $\varphi:[0, \infty) \rightarrow[0, \infty)$ which satisfies the following conditions:

(i) $\varphi$ is increasing;

(ii) for each $x \geq 0$, there exists some $\psi \in \Psi$ such that $\varphi(x) \leq \psi(x / 2)$. 
We assume that $K_{1}, K_{2}, f$, g satisfy the following conditions.

Assumption 4.1. (i) $K_{1}(t, s) \geq 0$ and $K_{2}(t, s) \leq 0$ for all $t, s \in[a, b]$;

(ii) There exist $\lambda, \mu>0$ and $\varphi \in \Theta$ such that for all $x, y \in \mathbb{R}, x \geq y$,

$$
0 \leq f(t, x)-f(t, y) \leq \lambda \varphi(x-y)
$$

and

$$
-\mu \varphi(x-y) \leq g(t, x)-g(t, y) \leq 0 ;
$$

(iii) $(\lambda+\mu) \cdot \sup _{t \in I} \int_{a}^{b}\left(K_{1}(t, s)-K_{2}(t, s)\right) d s \leq 1$.

Definition 4.2. An element $(\tau, \beta) \in X \times X$ with $X=C(I, \mathbb{R})$ is called a coupled lower and upper solution of the integral equation (4.1) if for all $t \in I$,

$$
\tau(\mathrm{t}) \leq \int_{\mathrm{a}}^{\mathrm{b}} \mathrm{K}_{1}(\mathrm{t}, \mathrm{s})(\mathrm{f}(\mathrm{s}, \tau(\mathrm{s}))+\mathrm{g}(\mathrm{s}, \beta(\mathrm{s}))) \mathrm{ds}+\int_{\mathrm{a}}^{\mathrm{b}} \mathrm{K}_{2}(\mathrm{t}, \mathrm{s})(\mathrm{f}(\mathrm{s}, \beta(\mathrm{s}))+\mathrm{g}(\mathrm{s}, \tau(\mathrm{s}))) \mathrm{ds}+\mathrm{h}(\mathrm{t})
$$

and

$$
\beta(t) \geq \int_{a}^{b} K_{1}(t, s)(f(s, \beta(s))+g(s, \tau(s))) d s+\int_{a}^{b} K_{2}(t, s)(f(s, \tau(s))+g(s, \beta(s))) d s+h(t) .
$$

Theorem 4.3. Consider the integral equation (4.1) with $K_{1}, K_{2} \in C(I \times I, \mathbb{R}), f, g \in C(I \times \mathbb{R}, \mathbb{R})$ and $h$ $\in C(I, \mathbb{R})$. Suppose that there exists a coupled lower and upper solution $(\tau, \beta)$ of (4.1) with $\tau \leq \beta$ and that Assumption 4.1 is satisfied. Then the integral equation (4.1) has a solution.

Proof. Consider the natural order relation on $\mathrm{X}=\mathrm{C}(\mathrm{I}, \mathbb{R})$; that is, for $\mathrm{x}, \mathrm{y} \in \mathrm{C}(\mathrm{I}, \mathbb{R})$

$$
x \leq y \Leftrightarrow x(t) \leq y(t), \forall t \in I
$$

It is well known that $X$ is a complete metric space with respect to the sup metric

$$
d(x, y)=\sup _{t \in I}|x(t)-y(t)|, \quad x, y \in C(I, \mathbb{R}) .
$$

Also, $\mathrm{X} \times \mathrm{X}=\mathrm{C}(\mathrm{I}, \mathbb{R}) \times \mathrm{C}(\mathrm{I}, \mathbb{R})$ is a partially ordered set under the following order relation in $\mathrm{X} \times \mathrm{X}$

$$
(x, y),(u, v) \in X \times X,(x, y) \leq(u, v) \Leftrightarrow x(t) \leq u(t) \text { and } y(t) \geq v(t), \quad \forall t \in I .
$$

Define $F: X \times X \rightarrow X$ by

$$
F(x, y)(t)=\int_{a}^{b} K_{1}(t, s)(f(s, x(s))+g(s, y(s))) d s+\int_{a}^{b} K_{2}(t, s)(f(s, y(s))+g(s, x(s))) d s+h(t)
$$

for all $t \in[a, b]$.

We now show that $F$ has the mixed monotone property. For $x_{1}(t) \leq x_{2}(t)$ for all $t \in[a, b]$ we have

$$
\begin{aligned}
F\left(x_{1}, y\right)(t)-F\left(x_{2}, y\right)(t) & =\int_{a}^{b} K_{1}(t, s)\left(f\left(s, x_{1}(s)\right)+g(s, y(s))\right) d s \\
& +\int_{a}^{b} K_{2}(t, s)\left(f(s, y(s))+g\left(s, x_{1}(s)\right)\right) d s+h(t)
\end{aligned}
$$




$$
\begin{aligned}
& -\int_{a}^{b} K_{1}(t, s)\left(f\left(s, x_{2}(s)\right)+g(s, y(s))\right) d s \\
& -\int_{a}^{b} K_{2}(t, s)\left(f(s, y(s))+g\left(s, x_{2}(s)\right)\right) d s-h(t) \\
& =\int_{a}^{b} K_{1}(t, s)\left(f\left(s, x_{1}(s)\right)-f\left(s, x_{2}(s)\right)\right) d s \\
& +\int_{a}^{b} K_{2}(t, s)\left(g\left(s, x_{1}(s)\right)-g\left(s, x_{2}(s)\right)\right) d s \leq 0,
\end{aligned}
$$

by Assumption 4.1. Hence $F\left(x_{1}, y\right)(t) \leq F\left(x_{2}, y\right)(t), \forall t \in$ I; that is, $F\left(x_{1}, y\right) \leq F\left(x_{2}, y\right)$.

Similarly, if $y_{1} \geq y_{2}$, that is, $y_{1}(t) \geq y_{2}(t)$, for all $t \in[a, b]$, we have

$$
\begin{aligned}
F\left(x, y_{1}\right)(t)-F\left(x, y_{2}\right)(t)= & \int_{a}^{b} K_{1}(t, s)\left(f(s, x(s))+g\left(s, y_{1}(s)\right)\right) d s \\
& +\int_{a}^{b} K_{2}(t, s)\left(f\left(s, y_{1}(s)\right)+g(s, x(s))\right) d s+h(t) \\
& -\int_{a}^{b} K_{1}(t, s)\left(f(s, x(s))+g\left(s, y_{2}(s)\right)\right) d s \\
& -\int_{a}^{b} K_{2}(t, s)\left(f\left(s, y_{2}(s)\right)+g(s, x(s))\right) d s-h(t) \\
= & \int_{a}^{b} K_{1}(t, s)\left(g\left(s, y_{1}(s)\right)-g\left(s, y_{2}(s)\right)\right) d s \\
& +\int_{a}^{b} K_{2}(t, s)\left(f\left(s, y_{1}(s)\right)-f\left(s, y_{2}(s)\right)\right) d s \leq 0,
\end{aligned}
$$

by Assumption 4.1. Hence $F\left(x, y_{1}\right)(t) \leq F\left(x, y_{2}\right)(t), \forall t \in I$; that is, $F\left(x, y_{1}\right) \leq F\left(x, y_{2}\right)$.

Therefore $\mathrm{F}$ satisfies mixed monotone property.

Next, we verify that $\mathrm{F}$ is $(\alpha, \psi)$ - weak contraction for some $\alpha: X^{2} \times X^{2} \rightarrow[0,+\infty)$. For $\mathrm{x} \geq \mathrm{u}, \mathrm{y} \leq \mathrm{v}$; that is, $x(t) \geq u(t), y(t) \leq v(t)$ for all $t \in I$, we have

$$
\begin{aligned}
F(x, y)(t)-F(u, v)(t)= & \int_{a}^{b} K_{1}(t, s)(f(s, x(s))+g(s, y(s))) d s \\
& +\int_{a}^{b} K_{2}(t, s)(f(s, y(s))+g(s, x(s))) d s \\
& -\int_{a}^{b} K_{1}(t, s)(f(s, u(s))+g(s, v(s))) d s \\
& -\int_{a}^{b} K_{2}(t, s)(f(s, v(s))+g(s, u(s))) d s . \\
= & \int_{a}^{b} K_{1}(t, s)(f(s, x(s))-f(s, u(s))+g(s, y(s))-g(s, v(s))) d s \\
& +\int_{a}^{b} K_{2}(t, s)(f(s, y(s))-f(s, v(s))+g(s, x(s))-g(s, u(s))) d s \\
= & \int_{a}^{b} K_{1}(t, s)[(f(s, x(s))-f(s, u(s)))-(g(s, v(s))-g(s, y(s)))] d s
\end{aligned}
$$




$$
\begin{aligned}
& -\int_{a}^{b} K_{2}(\mathrm{t}, \mathrm{s})[(\mathrm{f}(\mathrm{s}, \mathrm{v}(\mathrm{s}))-\mathrm{f}(\mathrm{s}, \mathrm{y}(\mathrm{s})))-(\mathrm{g}(\mathrm{s}, \mathrm{x}(\mathrm{s}))-\mathrm{g}(\mathrm{s}, \mathrm{u}(\mathrm{s})))] \mathrm{ds} \\
& \leq \int_{\mathrm{a}}^{\mathrm{b}} \mathrm{K}_{1}(\mathrm{t}, \mathrm{s})[\lambda \varphi(\mathrm{x}(\mathrm{s})-\mathrm{u}(\mathrm{s}))+\mu \varphi(\mathrm{v}(\mathrm{s})-\mathrm{y}(\mathrm{s}))] \mathrm{d} s \\
& -\int_{\mathrm{a}}^{\mathrm{b}} \mathrm{K}_{2}(\mathrm{t}, \mathrm{s})[\lambda \varphi(\mathrm{v}(\mathrm{s})-\mathrm{y}(\mathrm{s}))+\mu \varphi(\mathrm{x}(\mathrm{s})-\mathrm{u}(\mathrm{s}))] \mathrm{ds} .
\end{aligned}
$$

Since the function $\varphi$ is increasing and $x \geq u$ and $y \leq v$, we have

$$
\varphi(\mathrm{x}(\mathrm{s})-\mathrm{u}(\mathrm{s})) \leq \varphi\left(\sup _{\mathrm{t} \in \mathrm{I}}|\mathrm{x}(\mathrm{t})-\mathrm{u}(\mathrm{t})|\right)=\varphi(\mathrm{d}(\mathrm{x}, \mathrm{u}))
$$

and

$$
\varphi(\mathrm{v}(\mathrm{s})-\mathrm{y}(\mathrm{s})) \leq \varphi\left(\sup _{\mathrm{t} \in \mathrm{I}}|\mathrm{v}(\mathrm{t})-\mathrm{y}(\mathrm{t})|\right)=\varphi(\mathrm{d}(\mathrm{v}, \mathrm{y})) .
$$

Hence, using (4.5) and the fact that $\mathrm{K}_{2}(\mathrm{t}, \mathrm{s}) \leq 0$, we obtain

$$
\begin{aligned}
|\mathrm{F}(\mathrm{x}, \mathrm{y})(\mathrm{t})-\mathrm{F}(\mathrm{u}, \mathrm{v})(\mathrm{t})| \leq & \int_{\mathrm{a}}^{\mathrm{b}} \mathrm{K}_{1}(\mathrm{t}, \mathrm{s})[\lambda \varphi(\mathrm{d}(\mathrm{x}, \mathrm{u}))+\mu \varphi(\mathrm{d}(\mathrm{v}, \mathrm{y}))] \mathrm{ds} \\
& -\int_{\mathrm{a}}^{\mathrm{b}} \mathrm{K}_{2}(\mathrm{t}, \mathrm{s})[\lambda \varphi(\mathrm{d}(\mathrm{v}, \mathrm{y}))+\mu \varphi(\mathrm{d}(\mathrm{x}, \mathrm{u}))] \mathrm{ds}
\end{aligned}
$$

Since all of the quantities on the right hand side of (4.5) are non-negative, (4.6) holds.

Similarly, we can show that

$$
\begin{aligned}
|F(y, x)(t)-F(v, u)(t)| \leq & \int_{a}^{b} K_{1}(t, s)[\lambda \varphi(d(v, y))+\mu \varphi(d(x, u))] d s \\
& -\int_{a}^{b} K_{2}(t, s)[\lambda \varphi(d(x, u))+\mu \varphi(d(v, y))] d s .
\end{aligned}
$$

Summing (4.6) and (4.7), dividing by 2 , and then taking the supremum with respect to $t$ we get, by using (4.4) that

$$
\begin{aligned}
\frac{d(F(x, y)+F(u, v))+d(F(y, x)+F(v, u)}{2} & \leq(\lambda+\mu) \sup _{t \in I} \int_{a}^{b}\left(K_{1}(t, s)-K_{2}(t, s)\right) d s \cdot \frac{\varphi(d(v, y))+\varphi(d(x, u))}{2} \\
& \leq \frac{\varphi(d(v, y))+\varphi(d(x, u))}{2} .
\end{aligned}
$$

Since $\varphi$ is increasing,

$$
\varphi(\mathrm{d}(\mathrm{x}, \mathrm{u})) \leq \varphi(\mathrm{d}(\mathrm{x}, \mathrm{u})+\mathrm{d}(\mathrm{v}, \mathrm{y})), \quad \varphi(\mathrm{d}(\mathrm{v}, \mathrm{y})) \leq \varphi(\mathrm{d}(\mathrm{x}, \mathrm{u})+\mathrm{d}(\mathrm{v}, \mathrm{y}))
$$

and hence

$$
\begin{aligned}
\frac{\varphi(\mathrm{d}(\mathrm{v}, \mathrm{y}))+\varphi(\mathrm{d}(\mathrm{x}, \mathrm{u}))}{2} & \leq \varphi(\mathrm{d}(\mathrm{x}, \mathrm{u})+\mathrm{d}(\mathrm{v}, \mathrm{y})) \\
& \leq \psi\left(\frac{\mathrm{d}(\mathrm{x}, \mathrm{u})+\mathrm{d}(\mathrm{v}, \mathrm{y})}{2}\right)
\end{aligned}
$$

by the definition of $\varphi$. Thus

$$
\frac{d(F(x, y)+F(u, v))+d(F(y, x)+F(v, u))}{2} \leq \psi\left(\frac{d(x, u)+d(v, y)}{2}\right) .
$$


Define the mapping $\alpha: X^{2} \times X^{2} \rightarrow[0,+\infty)$ by

$\alpha((x, y),(u, v))=1$, if the pairs $(x, y)$ and $(u, v)$ are comparable with respect to the ordering in $\mathrm{X} \times \mathrm{X}$ and $\alpha((x, y),(u, v))=0$, otherwise.

Then, for all $(x, y),(u, v) \in \mathrm{X} \times \mathrm{X}$, by the mixed monotone property of $\mathrm{F}$, we have

$$
\begin{aligned}
& \alpha((x, y),(u, v)) \geq 1 \Rightarrow \mathrm{x} \geq \mathrm{u} \text { and } \mathrm{y} \leq \mathrm{v} \text { or } \mathrm{x} \leq \mathrm{u} \text { and } \mathrm{y} \geq \mathrm{v} \\
& \Rightarrow F(x, y) \geq F(u, v) \text { and } F(y, x) \leq F(v, u) \text { or } F(y, x) \geq F(v, u) \text { and } F(x, y) \leq F(u, v) \\
& \Rightarrow \alpha((F(x, y), F(y, x)),(F(u, v), F(v, u))) \geq 1 .
\end{aligned}
$$

Therefore, $\mathrm{F}$ is $\alpha$-admissible. Moreover, by the definition of $\alpha$ and $(4.8), \mathrm{F}$ is $(\alpha, \psi)$ - weak contraction.

Suppose that $\left\{u_{n}\right\}$ and $\left\{v_{n}\right\}$ be two convergent sequences in $X$, converging to $u$ and $v$ respectively. Let $u_{n} \leq u_{n+1}$ and $v_{n} \geq v_{n+1}$ for all $n>0$.

Then by definition of $\alpha$, we have $\alpha\left(\left(u_{n}(t), v_{n}(t)\right),\left(u_{n+1}(t), v_{n+1}(t)\right)\right) \geq 1$, for all $\mathrm{t} \in \mathrm{I}$ and $\mathrm{n}>0$. Since $\left\{\mathrm{u}_{\mathrm{n}}\right\}$ is an increasing sequence in $\mathrm{X}$ converging to $\mathrm{u}$, so that $\mathrm{u}_{\mathrm{n}} \leq \mathrm{u}$ for all $\mathrm{n}$. Similarly, $\left\{\mathrm{v}_{\mathrm{n}}\right\}$ is a decreasing sequence in $\mathrm{X}$ converging to $\mathrm{v}$, so that $\mathrm{v} \leq \mathrm{v}_{\mathrm{n}}$ for all $\mathrm{n}$. Again by definition of $\alpha$, we have $\alpha\left(\left(u_{n}, v_{n}\right),(u, v)\right) \geq 1$ for all $\mathrm{n}$. Therefore, the space $(\mathrm{X}, \mathrm{d}, \leq)$ is $\alpha$-regular.

Further, for any $x, y \in X, \max .\{x(t), y(t)\}$ and $\min .\{x(t), y(t)\}$, for each $t \in I$, are in $X$ and are the upper and lower bounds of $x, y$, respectively. Therefore, for every $(x, y),(u, v) \in X \times X$, there exists a $(\max .\{\mathrm{x}, \mathrm{u}\}, \min .\{\mathrm{y}, \mathrm{v})\}) \in \mathrm{X} \times \mathrm{X}$ that is comparable to $(\mathrm{x}, \mathrm{y})$ and $(\mathrm{u}, \mathrm{v})$. Then, again by the definition of $\alpha, \alpha((\mathrm{x}, \mathrm{y}),(\max .\{\mathrm{x}, \mathrm{u}\}, \min .\{\mathrm{y}, \mathrm{v})\})) \geq 1$ and $\alpha((\mathrm{u}, \mathrm{v}),(\max .\{\mathrm{x}, \mathrm{u}\}, \min .\{\mathrm{y}, \mathrm{v})\})) \geq 1$.

Finally, let $(\tau, \beta)$ be a coupled lower and upper solution of the integral equation (4.1), then we have $\tau(\mathrm{t}) \leq \mathrm{F}(\tau, \beta)(\mathrm{t})$ and $\beta(\mathrm{t}) \geq \mathrm{F}(\beta, \tau)(\mathrm{t})$ for all $\mathrm{t} \in[\mathrm{a}, \mathrm{b}]$, that is, $\tau \leq \mathrm{F}(\tau, \beta)$ and $\beta \geq \mathrm{F}(\beta, \tau)$. Then, by the definition of $\alpha, \alpha((\tau, \beta),(\mathrm{F}(\tau, \beta), \mathrm{F}(\beta, \tau))) \geq 1$. Therefore, Theorems 2.3 and 3.2 yield that $\mathrm{F}$ has a unique coupled fixed point $(x, y)$ and hence the system (4.1) has a unique solution.

\section{References}

[1] S. Banach, Surles operations dans les ensembles et leur application aux equation sitegrales, Fund. Math. 3 (1922), 133181.

[2] R.P. Agarwal, M. Meehan, D. O’Regan, Fixed Point Th. Appl., Camb. Univ. Press, 2001.

[3] R.P. Agarwal, M.A. El-Gebeily, D.O'Regan, Generalized contractions in partially ordered metric spaces, Applicab. Anal. 87 (1) (2008), 109-116.

[4] D.W. Boyd, J.S.W. Wong, On nonlinear contractions, Proc. Amer. Math. Soc. 20 (1969), 458-464.

[5] A. Branciari, A fixed point theorem for mappings satisfying a general contractive condition of integral type, Internat. J. Math. Math. Sc. 29 (9) (2002), 531-536.

[6] L. B. Ciri'c , A generalization of Banach's contraction principle, Proc. Amer. Math. Soc. 45 (1974), $267-273$. 
[7] J. Dugundji, A. Granas, Fixed Point Th., Springer, New York, USA, 2003.

[8] D. J. Guo, V. Lakshmikantham, Nonlinear Problems in Abstract Cones, Acad. Press, Boston, Mass, USA, 1988.

[9] A. Meir, E. Keeler, A theorem on contraction mappings, J. Math. Anal. Appl. 28 (1969), 326-329.

[10] J.J. Nieto and R. Rodriguez-Lopez, Contractive mapping theorems in partially ordered sets and applications to ordinary differential equations, Order 22 (3) (2005), 223-239.

[11] B.E. Rhoades, A comparison of various definitions of contractive mappings, Trans. Amer. Math. Soc. 226 (1977), 257290.

[12] D.R. Smart, Fixed Point Theorems, Camb. Univ. Press, London, UK, 1974.

[13] T. Suzuki, Meir-Keeler contractions of integral type are still Meir-Keeler contractions, Internat. J. Math. Math. Sc., Article ID 39281, 6 pages, 2007.

[14] T. Suzuki, A generalized Banach contraction principle that characterizes metric completeness, Proc. Amer. Math. Soc. $136(5)$ (2008), 1861-1869.

[15] E. Zeidler, Nonlinear Functional Analysis and Its Applications I: Fixed-Point Theorems, Springer, Berlin, Germany, 1986.

[16] M. Turinici, Abstract comparison principles and multivariable Gronwall-Bellman inequalities, J. Math. Anal. Appl. 117 (1) (1986), 100-127.

[17] A.C.M. Ran, M.C.B. Reurings, A fixed point theorem in partially ordered sets and some applications to matrix equations, Proc. Amer. Math. Soc. 132 (5) (2004), 1435-1443.

[18] D. Guo, V. Lakshmikantham, Coupled fixed points of nonlinear operators with applications, Nonlinear Analysis 11 (5) (1987), 623-632.

[19] T.G. Bhaskar, V. Lakshmikantham, Fixed point theorems in partially ordered metric spaces and applications, Nonlinear Anal.: TMA 65 (7) (2006), 1379-1393.

[20] V. Berinde, Generalized coupled fixed point theorems for mixed monotone mappings in partially ordered metric spaces, Nonlinear Anal. TMA 74 (2011), 7347-7355.

[21] V. Lakshmikantham, Lj.B. Ciric, Coupled fixed point theorems for nonlinear contractions in partially ordered metric spaces, Nonlinear Anal. 70 (2009), 4341-4349.

[22] Binayak S. Choudhury, A. Kundu, A coupled coincidence point result in partially ordered metric spaces for compatible mappings. Nonlinear Anal. 73 (2010), 2524-2531.

[23] A. Alotaibi, S.M. Alsulami, Coupled coincidence points for monotone operators in partially ordered metric spaces, Fixed Point Th. Appl., 2011, 44 (2011).

[24] N.V. Luong, N.X. Thuan, Coupled fixed point in partially ordered metric spaces and applications, Nonlinear Anal. 74 (2011), 983-992.

[25] N. Hussain, A. Latif, M.H. Shah, Coupled and tripled coincidence point results without compatibility, Fixed Point Th. Appl. 2012, 77(2012), doi: 10.1186/1687-1812-2012-77.

[26] R. Saadati, S.M. Vaezpour, P. Vetro, B.E. Rhoades, Fixed point theorems in generalized partially ordered $G$-metric spaces, Math. Comput. Modelling 52 (2010), 797-801.

[27] B. Samet, Calogero Vetro, Coupled fixed point theorems for multi-valued nonlinear contraction mappings in partially ordered metric spaces, Nonlinear Anal.: TMA 74 (12) (2011), 4260-4268.

[28] W. Shatanawi, Partially ordered cone metric spaces and coupled fixed point results, Comput. Math. Appl. 60 (8) (2010), $2508-2515$. 
[29] W. Shatanawi, B. Samet, M. Abbas, Coupled fixed point theorems for mixed monotone mappings in ordered partial metric spaces, Math. Com. Modelling, doi:10.1016/j.mcm.2011.08.042.

[30] W. Sintunavarat, Y.J. Cho, P. Kumam, Coupled coincidence point theorems for contractions without commutative condition in intuitionistic fuzzy normed spaces, Fixed Point Th. Appl., 2011, 2011:81.

[31] W. Sintunavarat, Y.J. Cho, P. Kumam, Coupled fixed point theorems for weak contraction mapping under F-invariant set, Abstr. Appl. Anal. 2012, Article ID 324874, 15 pages, 2012.

[32] W. Sintunavarat, P. Kumam, Coupled best proximity point theorem in metric spaces, Fixed Point Th. Appl., 2012, 2012:93.

[33] H. Aydi, E. Karapınar, W. Shatanawi, Coupled fixed point results for $(\psi, \phi)$-weakly contractive condition in ordered partial metric spaces, Comput. Math. Appl. 62 (12) (2011), 4449-4460.

[34] M.E. Gordji, Y.J. Cho, S. Ghods, M. Ghods, M.H. Dehkordi, Coupled fixed point theorems for contractions in partially ordered metric spaces and applications, Math. Prob. Engg., 2012, Article ID 150363, 20 pages, 2012.

[35] B. Samet, Coupled fixed point theorems for a generalized Meir-Keeler contraction in partially ordered metric spaces, Nonlinear Anal. 72 (12) (2010), 4508-4517.

[36] T. Abdeljawad, H. Aydi, E. Karapınar, Coupled fixed points for Meir-Keeler contractions in ordered partial metric spaces, Math. Prob. Engg., 2012, Article ID 327273, 20 pages, doi:10.1155/2012/327273.

[37] V. Berinde, M. Pacurar, Coupled fixed point theorems for generalized symmetric Meir-Keeler contractions in ordered metric spaces, Fixed Point Th. Appl., 2012, 2012:115, doi:10.1186/1687-1812-2012-115.

[38] M. Jain, K. Tas, S. Kumar, N. Gupta, Coupled common fixed points involving a $(\varphi, \psi)$-contractive condition for mixed $g$ monotone operators in partially ordered metric spaces, Journal of Inequalities and Applications, 2012, 2012:285.

[39] B. Samet, C. Vetro, P. Vetro, Fixed point theorems for $\alpha$ - $\psi$-contractive type mappings, Nonlinear Anal. 75 (2012), 2154 2165.

[40] M. Mursaleen, S.A. Mohiuddine, R.P Agarwal, Coupled fixed point theorems for $\alpha$ - $\psi$-contractive type mappings in partially ordered metric spaces, Fixed Point Theory and Applications 2012, 2012:228.

[41] E. Karapinar, R. Agarwal, A note on 'Coupled fixed point theorems for $\alpha$ - $\psi$-contractive type mappings in partially ordered metric spaces’, Fixed Point Theory and Applications 2013, 2013:216.

[42] M. Jain, K. Tas, B. E. Rhoades, N. Gupta, Coupled Fixed Point Theorems for Generalized Symmetric Contractions in Partially Ordered Metric Spaces and applications, J. Comput. Anal. Appl. vol. 16, no. 3, pp. 438 - 454, $2014 .$.

[43] M. Jain, K. Tas, S. Kumar, N. Gupta, Coupled Fixed Point Theorems for a Pair of Weakly Compatible Maps along with CLRg Property in Fuzzy Metric Spaces. J. Appl. Math., vol. 2012, Article ID 961210, 13 pages, 2012. doi:10.1155/2012/961210

[44] M. Jain, K. Tas, N. Gupta, Coupled common fixed point results involving $(\varphi, \psi)$-contractions in ordered generalized metric spaces with application to integral equations. J. Inequal. Appl. 2013 2013:372.

[45] M. Jain, K. Tas, A Unique Coupled Common Fixed Point Theorem for Symmetric $(\varphi, \psi)$-Contractive Mappings in Ordered G -Metric Spaces with Applications, J. Appl. Math., vol. 2013, Article ID 134712, 13 pages, 2013. doi:10.1155/2013/134712.

[46] M. Jain, N. Gupta, C. Vetro, S. Kumar, Coupled Fixed Point Theorems for Symmetric $(\boldsymbol{\phi}, \boldsymbol{\psi})$-weakly Contractive Mappings in Ordered Partial Metric Spaces. The Journal of Mathematics and Computer Sciences 7(4), 230 - 304 (2013).

[47] B Samet, H Yazidi, Coupled fixed point theorems in partially ordered $\varepsilon$-chainable Metric spaces, The Journal of Mathematics and Computer Science 1(3) (2010) 142-151.

[48] S H Rasouli, M Bahrampour, A remark on the coupled fixed point theorems for mixed monotone operators in partially ordered metric spaces, The Journal of Mathematics and Computer Science 3(2) (2011) 246-261. 